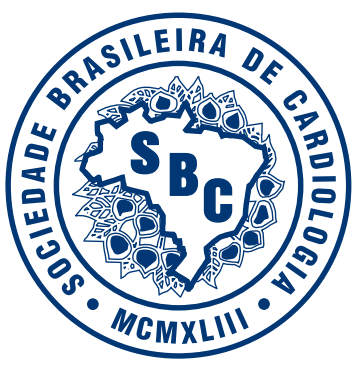

\title{
IV Diretriz Brasileira Sobre Dislipidemias e Prevenção da Aterosclerose Departamento de Aterosclerose da Sociedade Brasileira de Cardiologia
}

Coordenação Geral

\begin{tabular}{c} 
Andrei C. Sposito \\
Bruno Caramelli \\
Francisco A. H. Fonseca \\
Marcelo C. Bertolami \\
CoORDENADOR DE NorMATIZAÇõeS E DIRETRIZES \\
\hline Anis Rassi Jr. \\
EDITOR DA DIRETRIZ \\
Andrei C. Sposito \\
MeMBROS Do CoMITÊ
\end{tabular}

Abrahão Afiune Neto, Aguinaldo David Souza, Ana Maria Pitta Lottenberg, Ana Paula Chacra André A. Faludi, Andréia A. Loures-Vale, Antônio Carlos Carvalho, Bruce Duncan, Bruno Gelonese Carisi Polanczyk, Carlos Roberto M. Rodrigues Sobrinho, Carlos Scherr, Cynthia Karla Dikran Armaganijan, Emílio Moriguchi, Francisco Saraiva, Geraldo Pichetti, Hermes Toros Xavier Hilton Chaves, Jairo Lins Borges, Jayme Diament, Jorge Ilha Guimarães, José Carlos Nicolau José Ernesto dos Santos, José Jayme Galvão de Lima, José Luiz Vieira, José Paulo Novazzi José Rocha Faria Neto, Kerginaldo P. Torres, Leonor de Almeida Pinto, Liliana Bricarello Luiz Carlos Bodanese, Luiz Introcaso, Marcus Vinícius Bolívar Malachias, Maria Cristina Izar

Maria Eliane C. Magalhães, Maria Inês Schmidt, Mariléia Scartezini, Moacir Nobre Murilo Foppa, Neusa A. Forti, Otávio Berwanger, Otávio C. E. Gebara, Otávio Rizzi Coelho

Raul C. Maranhão, Raul Dias dos Santos Fo, Rosana Perim Costa, Sandhi Barreto Sérgio Kaiser, Silvia Ihara, Tales de Carvalho, Tania Leme Rocha Martinez, Waldir Gabriel Miranda Relvas, Wilson Salgado 
Nota: as recomendações emitidas neste documento, de forma geral, refletem as evidências de efetividade das intervenções. Sua finalidade principal é a de orientar os profissionais de saúde no atendimento de portadores de dislipidemias na tentativa de prevenir a aterosclerose ou reduzir suas complicações. Ele não trata de forma sistemática de análises de custo-efetividade. Desta forma, não deve ser encarado como um guia global absoluto para serviços preventivos de saúde pública.

\section{METABOLISMO LIPÍDICO}

Aspectos gerais

Dos pontos de vista fisiológico e clínico, os lípides biologicamente mais relevantes são os fosfolípides, o colesterol, os triglicérides (TG) e os ácidos graxos. Os fosfolípides formam a estrutura básica das membranas celulares. O colesterol é precursor dos hormônios esteróides, dos ácidos biliares e da vitamina D. Além disso, como constituinte das membranas celulares, o colesterol atua na fluidez destas e na ativação de enzimas aí situadas. Os triglicérides são formados a partir de três ácidos graxos ligados a uma molécula de glicerol e constituem uma das formas de armazenamento energético mais importante no organismo, depositados nos tecidos adiposo e muscular.

Os ácidos graxos podem ser classificados como saturados (sem duplas ligações entre seus átomos de carbono), mono ou polinsaturados de acordo com o número de ligações duplas na sua cadeia. Os ácidos graxos saturados mais freqüentemente presentes em nossa alimentação são: láurico, mirístico, palmítico e esteárico (que variam de 12 a 18 átomos de carbono). Entre os monoinsaturados, o mais freqüente é o ácido oléico que contém 18 átomos de carbono. Quanto aos polinsaturados, podem ser classificados como ômega-3 (eicosapentaenóico, docosahexaenóico e linolênico), ou ômega-6 (linolêico) de acordo com presença da primeira dupla ligação entre os carbonos, a partir do grupo hidroxila.

\section{Lipoproteínas - estrutura e função}

As lipoproteínas permitem a solubilização e transporte dos lípides, que são substâncias geralmente hidrofóbicas, no meio aquoso plasmático. São compostas por lípides e proteínas denominadas apolipoproteínas (apos). As apos têm diversas funções no metabolismo das lipoproteínas como a formação intracelular das partículas lipoprotéicas, caso das apos B100 e $\mathrm{B} 48$, ligantes a receptores de membrana como as apos B100 e E, ou co-fatores enzimáticos, como as apos CII, CIII e Al.

Existem quatro grandes classes de lipoproteínas separadas em dois grupos: (i) as ricas em TG, maiores e menos densas, representadas pelos quilomícrons, de origem intestinal, e pelas lipoproteínas de densidade muito baixa ou "very low density lipoprotein" (VLDL), de origem hepática; e (ii) as ricas em colesterol de densidade baixa "low density lipoprotein" (LDL) e de densidade alta ou "high density lipoprotein" (HDL). Existe ainda uma classe de lipoproteínas de densidade intermediária ou "intermediary density lipoprotein" (IDL) e a lipoproteína (a) [Lp(a)], que resulta da ligação covalente de uma partícula de LDL à apo (a). A função fisiológica da Lp(a) não é conhecida, mas, em estudos mecanísticos e observacionais, ela tem sido associada à formação e progressão da placa aterosclerótica. No entanto, como será discutido posteriormente, dificuldades técnicas laboratoriais limitam sua utilização como marcador da doença aterosclerótica.

Os quilomícrons são responsáveis pelo transporte dos lípides absorvidos pelo intestino, originários da dieta e da circulação entero-hepática. No fígado, o conteúdo de colesterol é regulado por três mecanismos principais: a) síntese intracelular do colesterol; b) armazenamento após esterificação; c) excreção pela bile. Na luz intestinal, o colesterol é excretado na forma de metabólitos ou como ácidos biliares. Metade do colesterol biliar e aproximadamente 95\% dos ácidos biliares são reabsorvidos e retornam ao fígado pelo sistema porta (ciclo êntero-hepático).

O transporte de lípides de origem hepática ocorre por meio das VLDL, IDL e LDL. Os triglicérides das VLDL, assim como os dos quilomícrons, são hidrolisados pela lipase lipoprotéica. Esta enzima é estimulada pela apo Cll e inibida pela apo CIII. Os ácidos graxos são liberados para os tecidos e metabolizados. Por ação da lipase lipoprotéica, os quilomícrons e as VLDL, progressivamente depletados de TG, se transformam em remanescentes, também removidos pelo fígado por receptores específicos. Uma parte das VLDL dá origem às IDL, que são removidas rapidamente do plasma. O processo de catabolismo continua, envolvendo a ação da lipase hepática e resultando nas LDL, que permanecem por longo tempo no plasma. Esta lipoproteína tem um conteúdo apenas residual de triglicérides e é composta principalmente de colesterol e uma única apolipoproteína, a apo B100. As LDL são removidas pelo fígado através dos receptores $\mathrm{B} / \mathrm{E}$. A expressão desses receptores é a principal responsável pelo nível de colesterol no sangue e depende da atividade da enzima hidroxi-metil-glutaril (HMG) CoA redutase que é a enzima-chave intracelular para síntese do colesterol hepático. No interior das células, o colesterol livre é esterificado para depósito por ação da enzima acil colesterol-acil transferase (ACAT). As VLDL trocam TG por ésteres de colesterol com as HDL e LDL por intermédio da ação da proteína de transferência de colesterol esterificado ou "cholesterol ester transfer protein" (CETP). As partículas de HDL são formadas no fígado, no intestino e na circulação e seu principal conteúdo protéico é representado pelas apos A-I e A-II. O colesterol livre da HDL, recebido das membranas celulares, é esterificado por ação da lecitina-colesterolaciltransferase (LCAT). A apo A1, principal proteína da HDL, é co-fator dessa enzima. O processo de esterificação do colesterol, que ocorre principalmente nas HDL, é fundamental para sua estabilização e transporte no plasma, no centro desta partícula. A HDL transporta o colesterol até o fígado onde este é captado pelos receptores SR-B1. O circuito de transporte do colesterol dos tecidos periféricos para o fígado é denominado transporte reverso do colesterol. Neste transporte, é importante a ação do complexo "ATP Binding Cassete" A1 (ABC-A1) que facilita a extração do colesterol da célula pelas HDL. A HDL também tem outras ações que contribuem para a proteção do leito vascular contra a aterogênese, tais como a remoção de lípides oxidados da LDL, inibição da fixação de moléculas de adesão e monócitos ao endotélio e estimulação da liberação de óxido nítrico. 


\section{Diretriz}

Além das diferenças em tamanho, densidade e composição química, as lipoproteínas podem diferir entre si através da modificação in vivo por oxidação, glicação ou dessialização. Estas modificações influenciam seu papel no metabolismo lipídico e no processo aterogênico.

\section{Bases fisiopatológicas das dislipidemias primárias}

O acúmulo de quilomícrons e/ou de VLDL no compartimento plasmático resulta em hipertrigliceridemia e decorre da diminuição da hidrólise dos triglicérides destas lipoproteínas pela lipase lipoprotéica ou do aumento da síntese de VLDL. Variantes genéticas das enzimas ou apolipoproteínas relacionadas a estas lipoproteínas podem causar ambas alterações metabólicas, aumento de síntese ou redução da hidrólise.

O acúmulo de lipoproteínas ricas em colesterol como a LDL no compartimento plasmático resulta em hipercolesterolemia. Este acúmulo pode ocorrer por doenças monogênicas, em particular, por defeito no gene do receptor de LDL ou no gene da apo B100. Centenas de mutações do receptor de LDL foram detectadas em portadores de hipercolesterolemia familiar, algumas causando redução de sua expressão na membrana, outras, deformações na sua estrutura e função. Mutação no gene que codifica a apo B100 pode também causar hipercolesterolemia através da deficiência no acoplamento da LDL ao receptor celular. Mais comumente, a hipercolesterolemia resulta de mutações em múltiplos genes envolvidos no metabolismo lipídico, as hipercolesterolemias poligênicas. Nestes casos, a interação entre fatores genéticos e ambientais determina o fenótipo do perfil lipídico.

\section{ATEROGÊNESE}

A aterosclerose é uma doença inflamatória crônica de origem multifatorial que ocorre em resposta à agressão endotelial, acometendo principalmente a camada íntima de artérias de médio e grande calibre.

A formação da placa aterosclerótica inicia-se com a agressão ao endotélio vascular devida a diversos fatores de risco como elevação de lipoproteínas aterogênicas (LDL, IDL, VLDL, remanescentes de quilomícrons), hipertensão arterial ou tabagismo. Como conseqüência, a disfunção endotelial aumenta a permeabilidade da íntima às lipoproteínas plasmáticas favorecendo a retenção das mesmas no espaço subendotelial. Retidas, as partículas de LDL sofrem oxidação, causando a exposição de diversos neo-epítopos, tornando-as imunogênicas. O depósito de lipoproteínas na parede arterial, processo-chave no início da aterogênese, ocorre de maneira proporcional à concentração dessas lipoproteínas no plasma.

Além do aumento da permeabilidade às lipoproteínas, outra manifestação da disfunção endotelial é o surgimento de moléculas de adesão leucocitária na superfície endotelial, processo estimulado pela presença de LDL oxidada. As moléculas de adesão são responsáveis pela atração de monócitos e linfócitos para a parede arterial. Induzidos por proteínas quimiotáticas, os monócitos migram para o espaço subendotelial onde se diferenciam em macrófagos, que por sua vez captam as LDL oxidadas. Os macrófagos repletos de lípides são chamados células espumosas e são o principal componente das estrias gordurosas, lesões macroscópicas iniciais da aterosclerose.
Alguns mediadores da inflamação estimulam a migração e proliferação das células musculares lisas da camada média arterial. Estas, ao migrarem para a íntima, passam a produzir não só citocinas e fatores de crescimento, como também matriz extracelular que formará parte da capa fibrosa da placa aterosclerótica.

A placa aterosclerótica plenamente desenvolvida é constituída por elementos celulares, componentes da matriz extracelular e núcleo lipídico. Estes elementos formam na placa aterosclerótica, o núcleo lipídico, rico em colesterol e a capa fibrosa, rica em colágeno. As placas estáveis caracterizam-se por predomínio de colágeno, organizado em capa fibrosa espessa, escassas células inflamatórias e núcleo lipídico de proporções menores. As instáveis apresentam atividade inflamatória intensa, especialmente nas suas bordas laterais, com grande atividade proteolítica, núcleo lipídico proeminente e capa fibrótica tênue. A ruptura desta capa expõe material lipídico altamente trombogênico, levando à formação de um trombo sobrejacente. Este processo, também conhecido por aterotrombose, é um dos principais determinantes das manifestações clínicas da aterosclerose.

\section{EPIDEMIOLOGIA DA ATEROSCLEROSE NO BRASIL}

\section{Panorama nacional}

Durante os últimos trinta anos presenciamos declínio razoável da mortalidade por causas cardiovasculares em países desenvolvidos, enquanto elevações relativamente rápidas e substanciais têm ocorrido em países em desenvolvimento, dentre os quais o Brasil. De acordo com as projeções da Organização Mundial de Saúde, esta tendência de elevação na doença cardiovascular tende a persistir, agravando ainda mais o quadro de morbidade e mortalidade elevadas nestes países. Em nosso país, o panorama da saúde cardiovascular pode ser descrito resumidamente através dos seguintes dados.

\section{Tabagismo}

De acordo com dados do IBGE (1991) a prevalência de tabagismo em pessoas acima de 5 anos de idade foi de $24 \%$, com maior concentração na faixa etária entre 30 e 49 anos. Outros estudos realizados entre 1971 e 1988 mostraram taxas de prevalência variando de 35 a 40\%. Recentemente, no Estudo Transversal da Sociedade de Cardiologia do Estado de São Paulo (1999) as taxas de prevalência de tabagismo foram de $17 \%$, após avaliação de aproximadamente 20.000 indivíduos em 19 cidades.

\section{Hipertensão}

A estimativa de hipertensão arterial na população brasileira adulta de acordo com o Ministério da Saúde (1991) e IBGE (Censo Populacional de 1991) foi de 15\%. Entretanto, taxas mais elevadas foram encontradas em estudos transversais na cidade do Rio de Janeiro em 1990 e no Estado de São Paulo (25\%).

\section{Diabete melito}

Com base no Censo Nacional de Diabete de 1980, a 
prevalência ajustada por idade (30-69 anos) foi de 7,6\%, com variação de 5 a 10\% de acordo com a capital brasileira avaliada.

\section{Obesidade}

Aproximadamente $32 \%$ da população brasileira apresenta sobrepeso [Índice de Massa Corporal (IMC) $\geq 25$ )], sendo esta taxa de $38 \%$ para o sexo feminino e de $27 \%$ para o sexo masculino, de acordo com os dados do Ministério da Saúde de 1993. A obesidade (IMC > 30) foi encontrada em $8 \%$ da população brasileira.

\section{Dislipidemias}

Os níveis séricos de colesterol total (CT) foram avaliados no Brasil em regiões específicas. Estudo conduzido em nove capitais, envolvendo 8.045 indivíduos com idade mediana de $35+10$ anos, no ano de 1998, mostrou que 38\% dos homens e $42 \%$ das mulheres possuem CT > $200 \mathrm{mg} / \mathrm{dL}$. Neste estudo, os valores do CT foram mais altos no sexo feminino e nas faixas etárias mais elevadas.

\section{Evidências Científicas que Impactam na Prática Clínica}

\section{Importância de desfechos clínicos}

As evidências científicas que determinam mudanças na prática clínica devem ser baseadas nos desfechos de saúdedoença, como morte e incidência de doença. Dados de pesquisas que interferem em desfechos substitutos (marcadores fisiopatológicos, bioquímicos, etc.), têm menor impacto direto na prática clínica, embora possam ser relevantes para melhor compreensão da doença e desenvolvimento de metodologias diagnósticas e terapêuticas.

\section{Hierarquia das evidências}

Para situar o leitor sobre a robustez da recomendação, os graus de recomendação e níveis de evidência foram baseados nos parâmetros descritos na Tabela I.

\section{AVALIAÇÃO LABORATORIAL DAS DISLIPIDEMIAS}

O perfil lipídico é definido pelas determinações bioquímicas do CT, colesterol ligado à HDL ou HDL-colesterol (HDL-C), TG e do colesterol ligado à LDL ou LDL-colesterol (LDL-C) após jejum de 12 a 14 horas. O LDL-C pode ser calculado pela equação de Friedewald (LDL-C $=\mathrm{CT}$ - HDL-C - TG/5), onde $\mathrm{TG} / 5$ representa o colesterol ligado à VLDL ou VLDLcolesterol (VLDL-C), ou diretamente mensurado no plasma. Em pacientes com hipertrigliceridemia (TG $>400 \mathrm{mg} / \mathrm{dL}$ ), hepatopatia colestática crônica, diabete melito ou síndrome nefrótica, a equação é imprecisa. Nestes casos, o valor do LDL-C pode ser obtido por dosagem direta. Como o uso da fórmula de Friedewald é adequado à maioria dos pacientes e tem custo muito menor, seu uso foi considerado como padrão por essa Diretriz. Além das dosagens bioquímicas, fez-se costumeiramente por algum tempo a eletroforese de lipoproteínas. Atualmente, esse exame só é necessário em casos especiais, como na constatação de ausência de lipoproteínas.
Tabela I - Grau de recomendação e nível de evidência

\section{Grau de recomendação}

I: Existem consenso e evidência em favor da indicação

Ila: Existe divergência, mas a maioria aprova

Ilb: Existe divergência e divisão de opiniões

III: Não se recomenda

\section{Nível de evidência}

A: Múltiplos ensaios clínicos controlados, aleatorizados.

B: Um único estudo clínico controlado aleatorizado, estudos clínicos não aleatorizados ou estudos observacionais bem desenhados.

C: Série ou relatos de casos.

D: Consenso de especialistas.

Nos demais casos, a eletroforese de lipoproteínas não auxilia na tomada de decisões clínicas.

A determinação do perfil lipídico deve ser feita em indivíduos com dieta habitual, estado metabólico e peso estáveis por pelo menos duas semanas antes da realização do exame. Além disso, deve-se evitar a ingestão de álcool e atividade física vigorosa nas 72 e 24 horas que antecedem a coleta de sangue, respectivamente.

\section{Variações nas dosagens dos lípides}

A acurácia na determinação do perfil lipídico depende de variações que podem ser divididas em analíticas, quando relacionadas à metodologia e procedimentos utilizados pelos laboratórios e pré-analíticas, quando relacionadas a procedimentos de coleta e preparo da amostra ou a fatores intrínsecos do indivíduo como estilo de vida, uso de medicações, doenças associadas. Na Tabela II estão dispostas as principais causas de variação pré-analítica e as sugestões para evitá-las.

Pacientes com alterações no perfil lipídico devem ter seus exames confirmados pela repetição de nova amostra. A nova dosagem deverá ser realizada com o intervalo mínimo de uma semana e máximo de dois meses após a coleta da primeira amostra. Esse procedimento visa reduzir a variabilidade entre os ensaios e aumentar a precisão diagnóstica. A variação entre duas dosagens no mesmo indivíduo, ou intra-individual, resulta, portanto, da combinação entre as variações pré-analíticas e analíticas. Entre duas dosagens sucessivas, é aceita como adequada variação intra-individual igual ou inferior à disposta na Tabela III. Por exemplo, as concentrações de triglicérides podem ser superestimadas pelo aumento do glicerol livre, como no exercício recente, doença hepática aguda, diabete melito descompensado, nutrição parenteral ou medicação intravenosa contendo glicerol. Nesses casos, é recomendada reavaliação em momento clinicamente mais oportuno.

Caso a variação entre as duas dosagens seja superior à máxima aceitável, deve-se suspeitar de interferência préanalítica ou analítica e proceder-se a uma terceira dosagem. A realização da terceira dosagem deve ser conduzida com 


\section{Diretriz}

Tabela II - Principais fontes de variação pré-analítica e recomendações

\section{Os componentes do perfil lipídico sofrem flutuações ao longo do tempo, caracterizando a \\ Variabilidade biológica variabilidade biológica intraindividual. As variações médias em indivíduos saudáveis, em termos de Coeficiente de Variação, podem ser resumidas em: CT, HDL-C e LDL-C cerca de 10\% e para os TG, cerca de $25 \%$.}

Duração do jejum

Postura durante coleta

Duração do torniquete
A padronização para a coleta recomenda jejum de 12 a 14 horas. Intervalos maiores ou menores podem interferir nos resultados.

É recomendável que a punção venosa seja realizada no paciente sentado pelo menos por 10 a 15 minutos para evitar variações ortostáticas da volemia e garantir a consistência entre as dosagens.

Após 1 minuto de torniquete pode haver hemoconcentração e, com relação ao perfil lipídico, ocorrer aumento de cerca de 5\% no CT. Este efeito pode chegar a 10 a 15\% com durações superiores a 5 minutos. Visando minimizar o "efeito torniquete", este deverá ser desfeito tão logo a agulha penetre na veia.

$\begin{aligned} & \text { Tabela III - Variação intra-individual máxima aceitável estimada pelos } \\
& \text { coeficientes de variação biológico e analítico }\end{aligned}$
\begin{tabular}{|cccc} 
Dosagem & \multicolumn{3}{c|}{ Coeficiente de variação } \\
\hline & Biológico & Analítico & Total \\
\hline CT & $6,1 \%$ & $3,0 \%$ & $9,1 \%$ \\
\hline HDL-C & $7,4 \%$ & $6,0 \%$ & $13,4 \%$ \\
\hline LDL-C & $9,5 \%$ & $4,0 \%$ & $13,5 \%$ \\
\hline TG & $22,6 \%$ & $5,0 \%$ & $27,6 \%$ \\
\hline
\end{tabular}

atenção especial às condições pré-analíticas e de preferência com a mesma metodologia e no mesmo laboratório. Devese também checar a consistência entre as metodologias utilizadas e a certificação do laboratório de análises clínicas que realizou a dosagem. Garantindo-se esses cuidados, se ainda assim persistir a variação além da esperada, o paciente com possível diagnóstico de dislipidemia deverá ser encaminhado a um serviço especializado para investigação complementar, confirmação diagnóstica e intervenção terapêutica específica.

\section{Determinação laboratorial da Lp(a) e das apos Al e B}

Embora a Lp(a) esteja envolvida na aterogênese, os numerosos polimorfismos da apo (a) e as limitações da metodologia da sua dosagem limitam acentuadamente sua utilização de rotina. Com relação às apos $\mathrm{Al}$ e B, o elevado custo e a ausência de informação adicional clinicamente relevante na maioria dos indivíduos, limitam a utilização de suas determinações na prática clínica. Portanto, como rotina, as determinações das apos $\mathrm{B}$ e $\mathrm{Al}$ e da $\mathrm{Lp}(\mathrm{a})$ não são indicadas para avaliação ou estratificação do risco cardiovascular (grau de recomendação III, nível de evidência A).

\section{Não-HDL colesterol}

O uso do Não-HDL colesterol (Não-HDL-C) tem como finalidade melhorar a quantificação de lipoproteínas aterogênicas circulantes no plasma de indivíduos com hipertrigliceridemia. Nestes, além do aumento de LDL, ocorre também aumento do volume de outras lipoproteínas aterogênicas como IDL e VLDL. Em outras palavras, a
LDL que normalmente representa o fenótipo de 90\% das partículas aterogênicas no plasma passa a ser menos preponderante à medida que se elevam os níveis de TG. Por isso, em indivíduos com hipertrigliceridemia, o uso do Não-HDL-C estima melhor o volume total de lipoproteínas aterogênicas que o LDL-C. Consistentemente, nestes, a meta terapêutica nos hipertrigliceridêmicos é melhor discriminada pelo Não-HDL-C que pelo LDL-C. À luz das evidências clínicas atuais, no entanto, o uso do Não-HDL colesterol somente é indispensável nas hipertrigliceridemias graves (TG $>400 \mathrm{mg} / \mathrm{dL}$ ), quando não se pode calcular o LDL-C pela equação de Friedewald.

\section{CLASSIFICAÇÃO DAS DISLIPIDEMIAS}

As dislipidemias primárias ou sem causa aparente podem ser classificadas genotipicamente ou fenotipicamente através de análises bioquímicas. Na classificação genotípica, as dislipidemias se dividem em monogênicas, causadas por mutações em um só gene, e poligênicas, causadas por associações de múltiplas mutações que isoladamente não seriam de grande repercussão. A classificação fenotípica ou bioquímica considera os valores do CT, LDL-C, TG e HDL-C. Compreende quatro tipos principais bem definidos:

\section{a) Hipercolesterolemia isolada \\ Elevação isolada do LDL-C ( $\geq 160 \mathrm{mg} / \mathrm{dL})$.}

\section{b) Hipertrigliceridemia isolada}

Elevação isolada dos TG ( $\geq 150 \mathrm{mg} / \mathrm{dL})$, que reflete o aumento do volume de partículas ricas em TG como VLDL, IDL e quilomícrons. Como citado, a estimativa do volume das lipoproteínas aterogênicas pelo LDL-C torna-se menos precisa à medida que aumentam os níveis plasmáticos de lipoproteínas ricas em TG. Portanto, conforme referido acima, o valor do Não-HDL-C pode ser usado como indicador de diagnóstico e meta terapêutica nestas situações.

\section{c) Hiperlipidemia mista}

Valores aumentados de ambos LDL-C ( $\geq 160 \mathrm{mg} / \mathrm{dL}$ ) e TG ( $\geq 150 \mathrm{mg} / \mathrm{dL}$ ). Nestes indivíduos, pode-se também utilizar o 
Não-HDL-C como indicador e meta terapêutica. Nos casos com $\mathrm{TG} \geq 400 \mathrm{mg} / \mathrm{dL}$, quando o cálculo do LDL-C pela fórmula de Friedewald é inadequado, considerar-se-á hiperlipidemia mista se o CT for maior ou igual a $200 \mathrm{mg} / \mathrm{dL}$.

\section{d) HDL-C baixo}

Redução do HDL-C (homens $<40 \mathrm{mg} / \mathrm{dL}$ e mulheres $<50$ $\mathrm{mg} / \mathrm{dL}$ ) isolada ou em associação com aumento de LDL-C ou de TG.

\section{ESTRATIFICAÇÃO DE RISCO E METAS LIPÍDICAS PARA PREVENÇÃO E TRATAMENTO DA ATEROSCLEROSE}

Um evento coronariano agudo é a primeira manifestação da doença aterosclerótica em pelo menos metade dos indivíduos que apresentam essa complicação. Desta forma, a identificação dos indivíduos assintomáticos que estão mais predispostos é crucial para a prevenção efetiva com a correta definição das metas terapêuticas. A estimativa do risco de doença aterosclerótica resulta do somatório do risco causado por cada um dos fatores de risco mais a potenciação causada por sinergismos entre alguns desses fatores. Diante da complexidade destas interações, a atribuição intuitiva do risco freqüentemente resulta em subestimação ou superestimação dos casos de maior ou menor risco, respectivamente. Para contornar esta dificuldade, diversos algoritmos têm sido criados baseados em análises de regressão de estudos populacionais, através dos quais a identificação do risco global é aprimorada substancialmente. Dentre os algoritmos existentes, o Escore de Risco de Framingham (ERF) é o indicado por esta Diretriz. Nele se estima a probabilidade de ocorrer infarto do miocárdio ou morte por doença coronária no período de 10 anos em indivíduos sem diagnóstico prévio de aterosclerose clínica. Embora esta estimativa de risco seja sujeita a correções conforme indicadores epidemiológicos da população estudada, o ERF identifica adequadamente indivíduos de alto e baixo risco.

\section{Estratificação do Risco}

Fase 1 - Presença de doença aterosclerótica significativa ou de seus equivalentes

Conforme mencionado acima, o risco de doença aterosclerótica é estimado com base na análise conjunta de características que aumentam a chance de um indivíduo desenvolver a doença. Portanto, o mais claro identificador de risco é a manifestação prévia da própria doença. Desta forma, o primeiro passo na estratificação do risco é a identificação de manifestações clínicas da doença aterosclerótica ou de seus equivalentes, como a presença de diabete melito tipos 1 ou 2 (Tabela IV). Indivíduos assim identificados possuem risco maior do que $20 \%$ em 10 anos de apresentar novos eventos cardiovasculares (grau de recomendação I, nível de evidência A).

\section{Fase 2 - Escore de risco}

Entre os indivíduos sem doença aterosclerótica significativa, pode-se estimar pelo ERF aqueles de risco baixo (probabilidade
Tabela IV - Critérios para identificação de pacientes com alto risco de eventos coronários (Fase 1)

- Doença Arterial Coronária manifesta atual ou prévia (angina estável, isquemia silenciosa, síndrome coronária aguda ou cardiomiopatia isquêmica).

- Doença Arterial Cerebrovascular (acidente vascular cerebral isquêmico ou ataque isquêmico transitório)

- Doença aneurismática ou estenótica de aorta abdominal ou seus ramos

- Doença arterial periférica

- Doença Arterial Carotídea (Estenose maior ou igual a $50 \%$ )

- Diabete melito tipo 1 ou 2

menor que $10 \%$ de infarto ou morte por doença coronária no período de 10 anos) e risco alto (probabilidade maior do que $20 \%$ de infarto ou morte por doença coronária no período de 10 anos). Para os indivíduos identificados pelo ERF como portadores de risco intermediário (probabilidade entre $10 \%$ e $20 \%$ de infarto ou morte por doença coronária no período de 10 anos), maior atenção deverá ser dada aos fatores agravantes (Fase 3), para aperfeiçoar a acurácia do ERF nestes indivíduos. Na Tabela V, estão dispostos os critérios para cálculo de risco pelo ERF.

\section{Síndrome metabólica}

O excesso de peso associado ao acúmulo de gordura na região mesentérica, obesidade denominada do tipo central, visceral ou androgênica, está associado a maior risco de doença aterosclerótica. A medida da circunferência abdominal nos permite identificar portadores desta forma de obesidade e deve ser avaliada com o paciente de pé, ao final da expiração, no ponto médio entre o último arco costal e a crista ilíaca ântero-superior, com fita inelástica, em posição horizontal. Em geral, esses indivíduos apresentam dislipidemia (triglicérides elevados, HDL-C baixo, partículas de LDL pequenas e densas, hiperlipidemia pós prandial), resistência à insulina e hipertensão arterial sistêmica, condições que em conjunto caracterizam a síndrome metabólica. Esta Diretriz adotou os critérios da Federação Internacional de Diabetes (IDF) com valores diferenciados para a glicemia de jejum e para a circunferência abdominal respeitando as diferentes etnias (Tabela VI). O ERF deve ser igualmente utilizado em portadores de síndrome metabólica que não apresentem doença aterosclerótica significativa ou seus equivalentes. No entanto, em qualquer categoria de risco, a presença da síndrome metabólica constitui um fator agravante conforme Tabela VII (grau de recomendação Ila, nível de evidência B).

O diagnóstico de síndrome metabólica requer a presença de obesidade abdominal, como condição essencial e dois ou mais dos critérios expostos na Tabela VI.

Fase 3 - Fatores agravantes

A estimativa do risco de eventos coronarianos pelo ERF 


\section{Diretriz}

Tabela V - Escores de risco de Framingham (ERF) para cálculo do risco absoluto de infarto e morte em 10 anos para homens e mulheres (Fase 2)

\begin{tabular}{|c|c|c|c|c|c|c|c|c|c|c|c|}
\hline \multicolumn{6}{|c|}{ HOMENS } & \multicolumn{6}{|c|}{ MULHERES } \\
\hline Idade & & \multicolumn{4}{|c|}{ Pontos } & \multicolumn{2}{|c|}{ Idade } & \multicolumn{4}{|c|}{ Pontos } \\
\hline $20-34$ & & \multicolumn{4}{|c|}{-9} & \multicolumn{2}{|c|}{$20-34$} & \multicolumn{4}{|c|}{-7} \\
\hline $35-39$ & & \multicolumn{4}{|c|}{-4} & \multicolumn{2}{|c|}{$35-39$} & \multicolumn{4}{|c|}{-3} \\
\hline $40-44$ & & \multicolumn{4}{|c|}{0} & \multicolumn{2}{|c|}{$40-44$} & \multicolumn{4}{|c|}{0} \\
\hline $45-49$ & & \multicolumn{4}{|c|}{3} & \multicolumn{2}{|c|}{$45-49$} & \multicolumn{4}{|c|}{3} \\
\hline $50-54$ & & \multicolumn{4}{|c|}{6} & \multicolumn{2}{|c|}{$50-54$} & \multicolumn{4}{|c|}{6} \\
\hline $55-59$ & & \multicolumn{4}{|c|}{8} & \multicolumn{2}{|c|}{$55-59$} & \multicolumn{4}{|c|}{8} \\
\hline $60-64$ & & \multicolumn{4}{|c|}{10} & \multicolumn{2}{|c|}{$60-64$} & \multicolumn{4}{|c|}{10} \\
\hline $65-69$ & & & & & & $65-$ & & & 1 & & \\
\hline $70-74$ & & & & & & $70-$ & & & 1 & & \\
\hline $75-79$ & & & & & & $75-$ & & & 1 & & \\
\hline Colesterol & idade & idade & idade & idade & idade & Colesterol & idade & idade & idade & idade & idade \\
\hline $\begin{array}{l}\text { Total, } \\
\text { mg/dL }\end{array}$ & 20-39 & $40-49$ & 50-59 & $60-69$ & $70-79$ & $\begin{array}{l}\text { Total, } \\
\text { mg/dL }\end{array}$ & $20-39$ & $40-49$ & $50-59$ & $60-69$ & 70-79 \\
\hline$<160$ & 0 & 0 & 0 & 0 & 0 & $<160$ & 0 & 0 & 0 & 0 & 0 \\
\hline 160-199 & 4 & 3 & 2 & 1 & 0 & 160-199 & 4 & 3 & 2 & 1 & 1 \\
\hline $200-239$ & 7 & 5 & 3 & 1 & 0 & $200-239$ & 8 & 6 & 4 & 2 & 1 \\
\hline $240-279$ & 9 & 6 & 4 & 2 & 1 & $240-279$ & 11 & 8 & 5 & 3 & 2 \\
\hline$\geq 280$ & 11 & 8 & 5 & 3 & 1 & $\geq 280$ & 13 & 10 & 7 & 4 & 2 \\
\hline Fumo & idade & idade & idade & idade & idade & Fumo & idade & idade & idade & idade & idade \\
\hline & 20-39 & 40-49 & $50-59$ & $60-69$ & $70-79$ & & $20-39$ & $40-49$ & $50-59$ & $60-69$ & 70-79 \\
\hline Não & 0 & 0 & 0 & 0 & 0 & Não & 0 & 0 & 0 & 0 & 0 \\
\hline Sim & 8 & 5 & 3 & 1 & 1 & Sim & 9 & 7 & 4 & 2 & 1 \\
\hline HDL-coles & (mg/dL & & & Pontos & & HDL-cc & esterol ( & dL) & & Pontos & \\
\hline$\geq 60$ & & & & -1 & & & $\geq 60$ & & & -1 & \\
\hline $50-59$ & & & & 0 & & & $50-59$ & & & 0 & \\
\hline $40-49$ & & & & 1 & & & $40-49$ & & & 1 & \\
\hline$<40$ & & & & 2 & & & $<40$ & & & 2 & \\
\hline PA (sistólic & m Hg) & & o tratad & & tratada & PA (sist & lica, mm & & não tratada & & \\
\hline$<120$ & & & 0 & & 0 & & $=120$ & & 0 & & \\
\hline $120-129$ & & & 0 & & 1 & & $0-129$ & & 1 & & \\
\hline 130-139 & & & 1 & & 2 & & $0-139$ & & 2 & & \\
\hline $140-159$ & & & 1 & & 2 & & $0-159$ & & 3 & & \\
\hline$\geq 160$ & & & 2 & & 3 & & $\geq 160$ & & 4 & & \\
\hline
\end{tabular}

é menos precisa nos indivíduos de risco intermediário (nos quais ocorre a maioria dos eventos), na avaliação do risco cardiovascular de curto prazo e nos jovens e nas mulheres. A Tabela VII propõe agravantes que levam o indivíduo à categoria de risco imediatamente superior. Os pacientes de baixo e médio risco que apresentem critérios agravantes podem ser classificados em uma categoria de risco acima daquela estimada isoladamente pelo escore (grau de recomendação lla, nível de evidência $B$ ).

A utilização de testes diagnósticos bioquímicos e/ou 


\begin{tabular}{|c|c|c|c|}
\hline \multicolumn{4}{|c|}{$\begin{array}{c}\text { Continuação da Tabela V - Escores de risco de Framingham (ERF) para cálculo do risco absoluto de infarto e morte em } 10 \text { anos } \\
\text { para homens e mulheres (Fase 2) - Continuação. }\end{array}$} \\
\hline Total de pontos & Risco absoluto em 10 anos (\%) & Total de pontos & Risco absoluto em 10 anos (\%) \\
\hline$<0$ & $<1$ & $<9$ & $<1$ \\
\hline 0 & 1 & 9 & 1 \\
\hline 1 & 1 & 10 & 1 \\
\hline 2 & 1 & 11 & 1 \\
\hline 3 & 1 & 12 & 1 \\
\hline 4 & 1 & 13 & 2 \\
\hline 5 & 2 & 14 & 2 \\
\hline 6 & 2 & 15 & 3 \\
\hline 7 & 3 & 16 & 4 \\
\hline 8 & 4 & 17 & 5 \\
\hline 9 & 5 & 18 & 6 \\
\hline 10 & 6 & 19 & 8 \\
\hline 11 & 8 & 20 & 11 \\
\hline 12 & 10 & 21 & 14 \\
\hline 13 & 12 & 22 & 17 \\
\hline 14 & 16 & 23 & 22 \\
\hline 15 & 20 & 24 & 27 \\
\hline 16 & 25 & $\geq 25$ & $\geq 30$ \\
\hline$\geq 17$ & $\geq 30$ & & \\
\hline
\end{tabular}

de exames de imagem para detecção da aterosclerose subclínica não são preconizados como ferramentas de rotina na estratificação de risco, mas podem ser incorporados de forma individualizada em indivíduos que apresentem história familiar de doença aterosclerótica precoce ou que sejam considerados como de risco intermediário segundo o ERF (grau de recomendação Ila, nível de evidência B).

\section{Fase 4 - Metas terapêuticas e reavaliação do risco}

Todos os pacientes com dislipidemia isolada e aqueles com risco cardiovascular aumentado devem ser orientados para a instituição de medidas não-farmacológicas relacionadas à mudança do estilo de vida (MEV) (grau de recomendação I, nível de evidência A). O tratamento farmacológico deve ser iniciado naqueles de risco baixo (6 meses após) ou intermediário (3 meses após) que não atingirem as metas (Tabela VIII) após medidas não-farmacológicas. Nos indivíduos de alto risco as medidas não-farmacológicas e o tratamento com hipolipemiantes devem ser iniciados simultaneamente. Nos pacientes com doença aterosclerótica significativa, de acordo com evidências atuais, a obtenção do nível de LDLC igual ou inferior a $70 \mathrm{mg} / \mathrm{dL}$ traz redução adicional da incidência de eventos cardiovasculares. Portanto, essa Diretriz recomenda a meta de LDL-C igual ou inferior a $70 \mathrm{mg} / \mathrm{dL}$ para todos os indivíduos com doença aterosclerótica significativa (Tabela IX) (grau de recomendação I, nível de evidência A).

\section{TRATAMENTO NÃO MEDICAMENTOSO DAS DISLIPIDEMIAS E MEDIDAS DE PREVENÇÃO DA ATEROSCLEROSE}

\section{Terapia nutricional da hipercolesterolemia}

Há muito tem sido demonstrado que o aumento do consumo de gordura associa-se à elevação da concentração plasmática de colesterol e à maior incidência de aterosclerose coronária e aórtica. A terapia nutricional deve, portanto, ser adotada na prevenção e no tratamento das dislipidemias, onde o plano alimentar deverá contemplar questões culturais, regionais, sociais e econômicas, devendo ser agradável ao paladar e visualmente atraente. O paciente deverá receber também orientações relacionadas à seleção, quantidade, técnicas de preparo e substituições dos alimentos. Na Tabela X, estão expostas as recomendações nutricionais para tratamento da hipercolesterolemia (grau de recomendação I, nível de evidência B).

\section{Colesterol e ácidos graxos saturados}

Os conteúdos alimentares de gorduras saturadas e de colesterol influenciam diferentemente os níveis lipídicos plasmáticos, em especial a colesterolemia. A maioria da população absorve aproximadamente metade do colesterol presente na luz intestinal, enquanto uma minoria é hiperresponsiva, ou seja, absorve maior quantidade. A absorção de 


\section{Diretriz}

Tabela VI - Critérios diagnósticos para síndrome metabólica

\begin{tabular}{|ll}
\hline Critério & Definição \\
\hline Obesidade abdominal & \\
\hline Homens & \\
\hline $\begin{array}{l}\text { Brancos de origem europídea } \\
\text { e negros }\end{array}$ & $\geq 94 \mathrm{~cm}$ \\
\hline $\begin{array}{l}\text { Sul-asiáticos, ameríndios e } \\
\text { chineses }\end{array}$ & $\geq 90 \mathrm{~cm}$ \\
\hline Japoneses & $\geq 85 \mathrm{~cm}$ \\
\hline Mulheres & \\
\hline $\begin{array}{l}\text { Brancas de origem europídea, } \\
\text { negras, sul-asiáticas, } \\
\text { ameríndias e chinesas }\end{array}$ & $\geq 80 \mathrm{~cm}$ \\
\hline Japonesas & $\geq 90 \mathrm{~cm}$ \\
\hline TG & $\geq 150 \mathrm{mg} / \mathrm{dL}$ ou \\
& tratamento para \\
\hline HDL-colesterol & hipertrigliceridemia \\
\hline Homens & $<40 \mathrm{mg} / \mathrm{dL}$ \\
\hline Mulheres & $<50 \mathrm{mg} / \mathrm{dL}$ \\
\hline Pressão arterial sistêmica & \\
\hline Sistólica, ou & $\geq 130 \mathrm{~mm} \mathrm{Hg}$ ou \\
\hline Diastólica & tratamento para HAS \\
\hline Glicemia de jejum & $\geq 85 \mathrm{~mm} \mathrm{Hg}$ ou \\
& tratamento para HAS \\
\hline & $\geq 100 \mathrm{mg} / \mathrm{dL}$ ou \\
&
\end{tabular}

O diagnóstico de síndrome metabólica inclui a presença de obesidade abdominal, como condição essencial, e dois ou mais dos critérios acima.

\section{Tabela VII - Fatores agravantes de risco}

- História familiar de doença coronária prematura (parente de primeiro grau masculino $<55$ anos ou feminino $<65$ anos

- Síndrome metabólica

- Micro ou macroalbuminúria (>30 $\mu \mathrm{g} / \mathrm{min})$

- Hipertrofia ventricular esquerda

- Insuficiência renal crônica (creatinina $\geq 1,5 \mathrm{mg} / \mathrm{dL}$ ou clearance de creatinina $<60 \mathrm{ml} / \mathrm{min}$ )

- Proteína-C-reativa de alta sensibilidade $>3 \mathrm{mg} / \mathrm{L}$ (na ausência de etiologia não aterosclerótica)

- Exame complementar com evidência de doença aterosclerótica subclínica

- Escore de cálcio coronário > 100 ou > percentil 75 para idade ou sexo

- Espessamento de carótida (IMT) máximo $>1 \mathrm{~mm}$.

- Índice tornozelo braquial-ITB $<0,9$

gordura saturada, no entanto, não é limitada e, por isso, sua ingestão promove efeito mais intenso sobre a colesterolemia.
Tabela VIII - Medidas terapêuticas iniciais e período de reavaliação

\begin{tabular}{|lcc|}
\hline Estrato & $\begin{array}{c}\text { Medida } \\
\text { terapêutica inicial }\end{array}$ & $\begin{array}{c}\text { Reavaliação das } \\
\text { metas }\end{array}$ \\
\hline Baixo risco & MEV & 6 meses \\
\hline $\begin{array}{l}\text { Risco } \\
\text { intermediário }\end{array}$ & MEV meses \\
\hline Alto risco & $\begin{array}{c}\text { MEV + tratamento } \\
\text { farmacológico }\end{array}$ & 3 meses \\
\hline $\begin{array}{l}\text { Aterosclerose } \\
\text { manifesta }\end{array}$ & $\begin{array}{c}\text { MEV + tratamento } \\
\text { farmacológico }\end{array}$ & Individualizada \\
\hline
\end{tabular}

Tabela IX - Metas para terapêutica preventiva com hipolipemiantes

\begin{tabular}{|c|c|c|c|}
\hline \multicolumn{2}{|c|}{ Risco em 10 anos } & \multicolumn{2}{|c|}{ Meta terapêutica (mg/dL) } \\
\hline & & LDL-C* & Não-HDL-C \\
\hline Baixo risco & $<10 \%$ & $<160$ & $<190$ \\
\hline $\begin{array}{l}\text { Risco } \\
\text { intermediário }\end{array}$ & $\begin{array}{l}10 \mathrm{a} \\
20 \%\end{array}$ & $<130$ & $<160$ \\
\hline $\begin{array}{l}\text { Alto risco ou } \\
\text { diabéticos }\end{array}$ & $>20 \%$ & $\begin{array}{c}<100 \\
\text { (opcional } \\
<70 \text { ) }\end{array}$ & $\begin{array}{c}<130 \\
\text { (opcional } \\
<100 \text { ) }\end{array}$ \\
\hline \multirow[t]{2}{*}{$\begin{array}{l}\text { Aterosclerose } \\
\text { significativa }\end{array}$} & $>20 \%$ & $<70$ & $<100$ \\
\hline & & HDL-C & TG \\
\hline Homens & & $\geq 40$ & $<150$ \\
\hline Mulheres & & $\geq 50$ & $<150$ \\
\hline Diabéticos & & $\geq 50$ & $<150$ \\
\hline
\end{tabular}

* Estimado pela equação de Friedewald

Obs.: quando não se conseguem as metas, recomenda-se obtenção da maior redução possível.

Tabela X - Recomendações dietéticas para o tratamento das hipercolesterolemias

\begin{tabular}{|ll}
\hline Nutrientes & Ingestão recomendada \\
\hline $\begin{array}{l}\text { Gordura total } \\
\text { Ácidos graxos } \\
\text { saturados }\end{array}$ & $\leq 5 \%$ a $35 \%$ das calorias totais \\
\hline $\begin{array}{l}\text { Ácidos graxos } \\
\text { polinsaturados }\end{array}$ & $\leq 10 \%$ das calorias totais \\
\hline $\begin{array}{l}\text { Ácidos graxos } \\
\text { monoinsaturados }\end{array}$ & $\leq 20 \%$ das calorias totais \\
\hline Carboidratos & 50 a $60 \%$ das calorias totais \\
\hline Proteínas & Cerca de $15 \%$ das calorias totais \\
\hline Colesterol & $<200$ mg/dia \\
\hline Fibras & 20 a 30 g/d \\
\hline Calorias & Ajustado ao peso desejável \\
\hline
\end{tabular}

Para reduzir a ingestão de colesterol, deve-se diminuir o consumo de alimentos de origem animal, em especial as vísceras, leite integral e seus derivados, embutidos, frios, pele de aves e frutos do mar (camarão, ostra, marisco, polvo, lagosta). Para diminuir o consumo de ácidos graxos saturados, 
aconselha-se a redução da ingestão de gordura animal (carnes gordurosas, leite e derivados), de polpa e leite de coco e de alguns óleos vegetais, como os de dendê.

\section{Ácidos graxos insaturados}

Os ácidos graxos insaturados são classificados em duas categorias principais: polinsaturados representados pelas séries ômega-6 (linoléico e araquidônico) e ômega-3 (alfalinolênico, eicosapentaenóico-EPA e docosahexaenóicoDHA) e monoinsaturados representados pela série ômega-9 (oléico). O ácido linoléico é essencial e o precursor dos demais ácidos graxos polinsaturados da série ômega- 6 , cujas fontes alimentares são os óleos vegetais de soja, milho, e girassol. A substituição isocalórica dos ácidos graxos saturados por ácidos graxos polinsaturados reduz o CT e o LDL-C plasmáticos. Os ácidos graxos polinsaturados possuem o inconveniente de induzir maior oxidação lipídica e diminuir o HDL-C quando utilizados em grande quantidade. Os ácidos graxos ômega-3 (linolênico, EPA e DHA) são encontrados respectivamente nos vegetais (soja, canola e linhaça) e em peixes de águas frias (cavala, sardinha, salmão, arenque). Promovem redução dos triglicérides plasmáticos pela diminuição da síntese hepática de VLDL, podendo ainda exercer outros efeitos cardiovasculares, como redução da viscosidade do sangue, maior relaxamento do endotélio e também efeitos anti-arrítmicos. Os ácidos graxos monoinsaturados (oléico) exercem o mesmo efeito sobre a colesterolemia, sem, no entanto, diminuir o HDL-C e provocar oxidação lipídica. Suas principais fontes dietéticas são o óleo de oliva, óleo de canola, azeitona, abacate e oleaginosas (amendoim, castanhas, nozes, amêndoas).

\section{Ácidos graxos trans}

Os ácidos graxos trans são sintetizados durante o processo de hidrogenação dos óleos vegetais. Os ácidos graxos trans aumentam o LDL-c e reduzem o HDL-c, aumentando assim a razão LDL-C/HDL-C e, da mesma forma que outros ácidos graxos, aumentam os TG. A principal fonte de ácidos graxos trans na dieta é a gordura vegetal hidrogenada, utilizada no preparo de sorvetes cremosos, chocolates, pães recheados, molhos para salada, sobremesas cremosas, biscoitos recheados, alimentos com consistência crocante (nuggets, croissants, tortas), bolos industrializados, margarinas duras e alguns alimentos produzidos em redes de "fast-foods". Não há consenso em relação à quantidade máxima permitida na dieta, no entanto, recomenda-se que a ingestão de gordura trans deva ser menor que $1 \%$ das calorias totais da dieta (grau de recomendação Ila, nível de evidência D).

\section{Fibras}

São carboidratos complexos classificados de acordo com sua solubilidade, em solúveis e insolúveis. As fibras solúveis são representadas pela pectina (frutas) e pelas gomas (aveia, cevada e leguminosas: feijão, grão de bico, lentilha e ervilha). Estas fibras reduzem o tempo de trânsito gastrointestinal e a absorção enteral do colesterol. O farelo de aveia é o alimento mais rico em fibras solúveis e pode, portanto, diminuir moderadamente o colesterol sangüíneo. As fibras insolúveis não atuam sobre a colesterolemia, mas aumentam a saciedade, auxiliando na redução da ingestão calórica. São representadas pela celulose (trigo), hemicelulose (grãos) e lignina (hortaliças). A recomendação de ingestão de fibra alimentar total para adultos é de 20 a $30 \mathrm{~g} /$ dia, 5 a $10 \mathrm{~g}$ destas devendo ser solúveis, como medida adicional para a redução do colesterol (grau de recomendação Ila, nível de evidência B).

\section{Fitosteróis}

Os fitosteróis são encontrados apenas nos vegetais e desempenham funções estruturais análogas ao colesterol em tecidos animais. O $\beta$-sitosterol, extraído dos óleos vegetais é o principal fitosterol encontrado nos alimentos. Reduzem a colesterolemia por competirem com a absorção do colesterol da luz intestinal. Uma dieta balanceada com quantidades adequadas de vegetais fornece aproximadamente 200 a 400mg de fitosteróis e os níveis plasmáticos variam de 0,3 a $1,7 \mathrm{mg} / \mathrm{dL}$. No entanto, é necessária a ingestão de $2 \mathrm{~g} /$ dia de fitosteróis para a redução média de 10-15\% do LDL-C. Os fitosteróis não influenciam os níveis plasmáticos de HDL-C e de triglicérides. A ingestão de 3 a 4 g/dia de fitosteróis pode ser utilizada como adjuvante ao tratamento hipolipemiante (grau de recomendação lla, nível de evidência B).

\section{Proteína de soja}

A ingestão de proteína da soja (25 gramas /dia) pode reduzir o colesterol plasmático (-6\% do LDL-C) e, portanto, pode ser considerada como auxiliar no tratamento da hipercolesterolemia (grau de recomendação lla, nível de evidência B). Os dados disponíveis são contraditórios quanto aos efeitos sobre os TG e HDL-C. Estudos com maiores casuísticas e delineamentos mais específicos a esta questão serão necessários. As principais fontes de soja na alimentação são: feijão de soja, óleo de soja, queijo de soja (tofu), molho de soja (shoyo), farinha de soja, leite de soja e o concentrado protéico da soja. Este concentrado exclui a presença de gorduras, mantendo carboidratos e $75 \%$ da sua composição em proteínas e é amplamente utilizado como base de alimentos liofilizados e como "suplemento protéico".

\section{Antioxidantes}

Os antioxidantes, dentre eles os flavonóides, presentes na dieta podem potencialmente estar envolvidos na prevenção da aterosclerose por inibirem a oxidação das LDL, diminuindo sua aterogenicidade e, conseqüentemente, o risco de doença arterial coronária. Os flavonóides são antioxidantes polifenólicos encontrados nos alimentos, principalmente nas verduras, frutas (cereja, amora, uva, morango, jabuticaba), grãos, sementes, castanhas, condimentos e ervas e também em bebidas como vinho, suco de uva e chá. Não há estudos randomizados, controlados e com número suficiente de pacientes que demonstrem a prevenção de eventos clínicos relacionados à aterosclerose com suplementações com antioxidantes como, por exemplo, as vitaminas $\mathrm{E}, \mathrm{C}$ ou beta-caroteno. Não há evidência de que suplementos de vitaminas antioxidantes previnam manifestações clínicas da aterosclerose, portanto esses não são recomendados (grau de recomendação III, nível de evidência A). Alimentação rica em 


\section{Diretriz}

frutas e vegetais diversificados fornece doses apropriadas de substâncias antioxidantes, que certamente contribuirão para a manutenção da saúde (grau de recomendação lla, nível de evidência D).

\section{Terapia nutricional da hipertrigliceridemia}

Pacientes com níveis muito elevados de triglicérides e que apresentem quilomicronemia, devem reduzir a ingestão de gordura total da dieta. Recomenda-se a ingestão de no máximo 15\% das calorias diárias na forma de gordura (NCEP ATPIII). Na hipertrigliceridemia secundária à obesidade ou diabete, recomenda-se, respectivamente, dieta hipocalórica, adequação do consumo de carboidratos e gordura, controle da hiperglicemia, além da restrição total do consumo de álcool. (grau de recomendação lla, nível de evidência D)

\section{Atividade física}

A atividade física regular constitui medida auxiliar para o controle das dislipidemias e tratamento da doença arterial coronária (grau de recomendação I, nível de evidência A). A prática de exercícios físicos aeróbios promove redução dos níveis plasmáticos de TG, aumento dos níveis de HDL-C, porém sem alterações significativas sobre as concentrações de LDL-C. Indivíduos com disfunção ventricular, em recuperação de eventos cardiovasculares ou cirurgias, ou mesmo aqueles que apresentem sinais e sintomas com baixas ou moderadas cargas de esforço, devem ingressar em programas de reabilitação cardiovascular supervisionado, de preferência em equipe multidisciplinar.

Além da avaliação clínica, deve ser realizado um teste ergométrico ou teste cardio-respiratório em esforço (ergoespirometria) para determinação da capacidade física individual e da intensidade de treinamento a ser preconizada. O programa de treinamento físico, para a prevenção ou para a reabilitação, deve incluir exercícios aeróbios, tais como, caminhadas, corridas leves, ciclismo, natação. Os exercícios devem ser realizados de três a seis vezes por semana, em sessões de duração de 30 a 60 minutos. Nas atividades aeróbias, recomenda-se como intensidade a zona alvo situada entre 60 e $80 \%$ da freqüência cardíaca máxima ( $F C$ mx), estimada em teste ergométrico. Na vigência de medicamentos que modifiquem a FC mx, como os betaloqueadores, a zona alvo permanecerá 60 a $80 \%$ da FC mx obtida no teste em vigência do tratamento. Quando estiver disponível avaliação ergoespirométrica, a zona alvo deverá ser definida pela FC situada entre o limiar anaeróbio (limiar 1) e o ponto de compensação respiratória (limiar 2).

Caso não seja possível estimar a FC mx em teste ergométrico convencional ou os limiares 1 e 2 na ergoespirometria, as atividades devem ser controladas pela escala subjetiva de esforço, devendo ser caracterizadas como leves ou moderadas. O componente aeróbio das sessões de condicionamento físico deve ser acompanhado por atividades de aquecimento, alongamento e desaquecimento. Exercícios de resistência muscular localizada podem ser utilizados, com sobrecargas de até $50 \%$ da força de contração voluntária máxima, porém como complemento ao treinamento aeróbio.

\section{Cessação do Tabagismo}

A cessação do tabagismo constitui medida fundamental e prioritária na prevenção primária e secundária da aterosclerose (grau de recomendação I, nível de evidência D). Entre os métodos de suporte à cessação, os mais efetivos são: abordagem cognitivo-comportamental (motivação, estímulo e acompanhamento) e farmacoterapia (nicotínica e não-nicotínica). A terapia de reposição de nicotina (TRN) está disponível, no nosso meio, nas formas de adesivos de liberação transdérmica e goma de mascar. A TRN aumenta significativamente as taxas de cessação do fumo, mas deve ser utilizada com cautela em pacientes com doença cardiovascular que possa ser exacerbada pelo aumento da atividade simpática induzida pelo fármaco. Os medicamentos não nicotínicos são bupropiona, nortriptilina, vareniclina e a clonidina.

\section{TRATAMENTO MEDICAMENTOSO DAS DISLIPIDEMIAS}

Os hipolipemiantes devem ser empregados sempre que não houver efeito satisfatório das MEV ou impossibilidade de aguardar os efeitos da MEV por prioridade clínica. A escolha da classe terapêutica está condicionada ao tipo de dislipidemia presente.

\section{Medicamentos que atuam predominantemente na colesterolemia}

$\mathrm{Na}$ hipercolesterolemia isolada, os medicamentos recomendados são as estatinas, que podem ser administradas em associação à ezetimiba, colestiramina e eventualmente a fibratos ou ácido nicotínico.

\section{Estatinas ou inibidores da HMG-CoA redutase}

As estatinas são inibidores da HMG-CoA redutase, uma das enzimas chave na síntese intracelular do colesterol. Sua inibição reduz o conteúdo intracelular de colesterol e, como conseqüência, há aumento do número de receptores de LDL nos hepatócitos que então removem mais VLDL, IDL e LDL da circulação para repor o colesterol intracelular. Estes medicamentos reduzem o LDL-C de $15 \%$ a $55 \%$ em adultos. A duplicação das doses acrescenta em média $6 \%$ na redução de LDL-C. Reduzem os TG de $7 \%$ a $28 \%$ e elevam o HDL-C de $2 \%$ a $10 \%$. As estatinas reduzem a mortalidade cardiovascular e a incidência de eventos isquêmicos coronários agudos, necessidade de revascularização do miocárdio, AVC (grau de recomendação I e nível de evidência A).

As estatinas devem ser administradas por via oral, em dose única diária, preferencialmente à noite para os fármacos de curta meia-vida ou em qualquer horário naqueles com meiavida maiores como a atorvastina e a rosuvastatina. O efeito terapêutico só será mantido com doses diárias, não devendo o fármaco ser suspenso ou usado em dias alternados, salvo haja efeito colateral ou contra-indicação clínica. As doses recomendadas e a redução do LDL-C esperada encontramse na Tabela XI.

Os efeitos adversos são raros durante tratamento com estatinas. Os mais graves, como hepatite, miosite e 
rabdomiólise, são observados ainda mais raramente. No entanto, para identificar possíveis efeitos adversos recomenda-

\begin{tabular}{|c|c|c|}
\hline \multicolumn{3}{|c|}{ Tabela XI - Doses das estatinas e efeitos sobre o LDL-C } \\
\hline Fármaco & Doses & $\Delta$ LDL-C \\
\hline Sinvastatina & 20 a $80 \mathrm{mg}$ & $-27 \%$ a $42 \%$ \\
\hline Lovastatina & 10 a $80 \mathrm{mg}$ & $-21 \%$ a $41 \%$ \\
\hline Pravastatina & 20 a $40 \mathrm{mg}$ & $-20 \%$ a $33 \%$ \\
\hline Fluvastatina & 20 a $80 \mathrm{mg}$ & $-15 \%$ a $37 \%$ \\
\hline Atorvastatina & 10 a $80 \mathrm{mg}$ & $-37 \%$ a $55 \%$ \\
\hline Rosuvastatina & 10 a 40mg & $-43 \%$ a $55 \%$ \\
\hline
\end{tabular}

se a dosagem dos níveis basais de creatinofosfoquinase (CK) e de transaminases (especialmente de ALT) e a repetição na primeira reavaliação ou a cada aumento de dose.

Recomenda-se monitorização cuidadosa em pacientes que apresentarem dor muscular e ou aumento de CK de 3 a $7 \mathrm{X}$ o limite superior da normalidade (LSN). As estatinas devem ser suspensas caso ocorra um ou mais dos seguintes critérios: aumento progressivo da CK; aumento da CK acima de 10 vezes o LSN ou persistência dos sintomas musculares. Nestas situações, após normalização do distúrbio que levou à suspensão, a mesma estatina com dose menor pode ser reiniciada ou outra estatina pode ser tentada.

São evidências de hepatotoxicidade: icterícia, hepatomegalia, aumento de bilirrubina direta e do tempo de protrombina. Na ausência de obstrução biliar, a dosagem da bilirrubina direta é mais acurada que a simples dosagem das transaminases para identificação e avaliação prognóstica de hepatotoxicidade. Nos casos com identificação objetiva de hepatotoxicidade, ou seja dois ou mais dos referidos sinais, recomenda-se a suspensão da estatina e pesquisa da etiologia. Em pacientes assintomáticos, a elevação isolada de 1 a 3 vezes o LSN das transaminases não justifica a suspensão do tratamento com estatina. Caso ocorra elevação isolada e superior a 3 vezes do LSN, um novo exame deverá ser feito para confirmação e outras etiologias avaliadas. Nestes casos, a redução da dose ou suspensão da estatina deverá ser baseada no julgamento clínico. Como referido previamente, não há contra-indicação do uso de estatinas em pacientes com doença hepática crônica, doença hepática ou esteatose não alcoólicas. Entretanto, é contra-indicado seu uso em pacientes com hepatopatias agudas.

\section{Ezetimiba}

A ezetimiba é um inibidor de absorção do colesterol que atua na borda em escova das células intestinais inibindo a ação da proteína transportadora do colesterol. Usada isoladamente, reduz cerca de 20 \% o LDL-C. Entretanto, variações de resposta podem ocorrer em indivíduos com absorção intestinal de colesterol acima ou abaixo da média populacional. Tem sido mais freqüentemente empregada em associação com as estatinas, em função da potenciação da redução do colesterol intracelular (redução da síntese pela estatina e da absorção intestinal pela ezetimiba). Em média, a dupla inibição proporciona reduções cerca de $20 \%$ maiores do LDL-C em comparação com a mesma estatina na mesma dose isoladamente.

No momento em que se redige essa Diretriz, estudos estão em andamento para avaliar o benefício clínico na redução de eventos cardiovasculares da associação deste fármaco associado à sinvastatina. Por enquanto, é recomendado o uso da ezetimiba isoladamente em casos de intolerância à estatina (grau de recomendação Ila e nível de evidência C) e em casos de sitosterolemia (grau de recomendação lla e nível de evidência C). Em associação com estatinas, a ezetimiba pode ser usada em casos de elevações persistentes do LDL-C apesar de doses adequadas de estatinas (grau de recomendação lla e nível de evidência B), em casos de hipercolesterolemia familiar homozigótica (grau de recomendação lla e nível de evidência C) ou como primeira opção terapêutica conforme indicação clínica (grau de recomendação lla e nível de evidência D).

A ezetimiba é empregada na dose única de $10 \mathrm{mg}$ ao dia. Pode ser administrada a qualquer hora do dia, com ou sem alimentação, não interferindo na absorção de gorduras e vitaminas lipossolúveis. Até o momento, raros efeitos colaterais têm sido apontados. Por precaução, recomenda-se que ela não seja utilizada em casos de dislipidemia com doença hepática aguda.

\section{Resinas de troca}

São fármacos que reduzem a absorção intestinal de sais biliares e, conseqüentemente, de colesterol. Com a redução da absorção, reduz-se o colesterol intracelular no hepatócito e, por este motivo, aumenta-se o número de receptores de LDL e a síntese de colesterol. O efeito sobre a colesterolemia é variável, reduzindo em média $20 \%$ dos valores basais de LDL-C. Esse efeito é potencializado pelo uso concomitante de estatinas. Ocasionalmente pode promover pequena elevação do HDL-C. A colestiramina, no estudo "Lipid Research Clinics", diminuiu a incidência de infarto do miocárdio em 19\%. Portanto, a colestiramina pode ser usada como adjuvante às estatinas no tratamento das hipercolesterolemias graves, podendo também ser utilizada em crianças, sendo a única liberada para mulheres no período reprodutivo sem método anticoncepcional efetivo (recomendação classe Ila, nível de evidência A).

A colestiramina (único inibidor disponível no Brasil) é apresentada em envelopes de $4 \mathrm{~g}$. A posologia inicial é de 4 g ao dia, podendo-se atingir no máximo 24 g/dia. Posologias superiores a $16 \mathrm{~g} /$ dia são dificilmente toleradas. A apresentação na forma "light" pode melhorar sua tolerância, mas contém fenilalanina, o que restringe seu uso em portadores de fenilcetonúria. Os principais efeitos colaterais relacionam-se ao aparelho digestivo, por interferir na motilidade intestinal: obstipação (particularmente em idosos), plenitude gástrica, náuseas e meteorismo, além de exacerbação de hemorróidas preexistentes. Raramente, pode ocorrer obstrução intestinal e acidose hiperclorêmica em idosos e crianças, respectivamente. Diminui eventualmente a absorção de vitaminas lipossolúveis (A, D, K, E) e de ácido fólico. Suplementação desses elementos a crianças, ou eventualmente a adultos, pode ser necessária. Entre os efeitos bioquímicos, verifica-se eventualmente aumento dos triglicérides, secundário ao estímulo à síntese hepática de VLDL. Como conseqüência, seu uso deve 


\section{Diretriz}

ser evitado na hipertrigliceridemia, particularmente se houver níveis acima de $400 \mathrm{mg} / \mathrm{dL}$. Qualquer medicamento concomitante, deve ser utilizado 1 hora antes ou 4 horas depois da administração das resinas.

\section{Medicamentos que atuam predominantemente nos TG}

No tratamento da hipertrigliceridemia isolada são prioritariamente indicados os fibratos e, em segundo lugar, o ácido nicotínico ou a associação de ambos. Pode-se ainda utilizar nesta dislipidemia, o ácido graxo ômega-3 isoladamente ou em associação com os fármacos. Na hiperlipidemia mista, o nível de triglicérides deverá orientar como o tratamento farmacológico será iniciado. Caso os níveis de TG estejam acima de $500 \mathrm{mg} / \mathrm{dL}$, deve-se iniciar o tratamento com um fibrato, adicionando se necessário ácido nicotínico e/ou ômega-3. Nesta situação, a meta prioritária é a redução do risco de pancreatite. Após reavaliação, caso haja a necessidade de redução adicional da colesterolemia, pode-se adicionar uma estatina e/ou outros redutores da colesterolemia. Nestes casos, deve ser evitado o uso do genfibrozil em associações entre fibratos e estatinas. Caso os níveis de triglicérides estejam abaixo de $500 \mathrm{mg} / \mathrm{dL}$, deve-se iniciar o tratamento com uma estatina isoladamente ou associada à ezetimiba, priorizandose a meta de LDL-C ou Não-HDL-C.

\section{Fibratos}

São fármacos derivados do ácido fíbrico que agem estimulando os receptores nucleares denominados "receptores alfa ativados de proliferação dos peroxissomas" (PPAR- $\alpha$ ). Esse estímulo leva a aumento da produção e ação da lipase lipoprotéica $(\mathrm{LPL})$, responsável pela hidrólise intravascular dos TG, e redução da Apo CIII, responsável pela inibição da LPL. O estímulo do PPAR- $\alpha$ pelos fibratos também leva a maior síntese da $\mathrm{Apo} \mathrm{Al}$, e conseqüentemente, de $\mathrm{HDL}$. Reduzem os níveis de triglicérides de 30 a 60\%. No entanto, a redução será mais pronunciada quanto maior o valor basal da trigliceridemia. Aumentam o HDL-C de 7 a 11\%. Sua ação sobre o LDL-C é variável, podendo diminuí-lo, não modificálo ou até aumentá-lo. Parecem ter efeitos pleiotrópicos, contudo, não se conhece a relevância clínica dos mesmos. O tratamento com genfibrozil reduziu a incidência de eventos cardiovasculares maiores e atenuou a progressão de aterosclerose em monoterapia.

Os fibratos são indicados no tratamento da hipertrigliceridemia endógena quando houver falha das medidas não farmacológicas. Quando os TG forem muito elevados (> $500 \mathrm{mg} / \mathrm{dL}$ ) são recomendados inicialmente, junto com as medidas não farmacológicas (recomendação classe I, nível de evidência A). No tratamento da dislipidemia mista com predomínio de hipertrigliceridemia (recomedação classe lla, nível de evidência C). As doses recomendadas encontram-se na Tabela XII.

É infreqüente a ocorrência de efeitos colaterais graves durante tratamento com fibratos, levando à necessidade da interrupção do tratamento. Podem ocorrer: distúrbios gastrintestinais, mialgia, astenia, litíase biliar (mais comum com clofibrato), diminuição de libido, erupção cutânea, prurido, cefaléia, perturbação do sono. Raramente observa-se aumento

Tabela XII - Doses dos fibratos disponíveis e efeito sobre HDL-C e TG
\begin{tabular}{|lccc}
\hline Medicamento & Dose $\mathbf{~ m g / d i a ~}$ & $\Delta$ HDL-C & $\Delta$ Triglicérides \\
\hline Bezafibrato & 400 a 600 & +5 a $30 \%$ & -15 a $55 \%$ \\
\hline Ciprofibrato & 100 & +5 a $30 \%$ & -15 a $45 \%$ \\
\hline Etofibrato & 500 & +5 a $20 \%$ & -10 a $30 \%$ \\
\hline Fenofibrato & 250 & +5 a $30 \%$ & -10 a $30 \%$ \\
\hline Genfibrozil & 600 a 1200 & +5 a $30 \%$ & -20 a $60 \%$ \\
\hline
\end{tabular}

de enzimas hepáticas e/ou CK, também de forma reversível com a interrupção do tratamento. Casos de rabdomiólise têm sido descritos com o uso da associação de estatinas com genfibrozil. Recomenda-se, por isso, evitar essa associação. Recomendase cautela nas seguintes condições clínicas: a) portadores de doença biliar; b) uso concomitante de anticoagulante oral, cuja posologia deve ser ajustada; c) pacientes com função renal diminuída; d) associação com estatinas.

\section{Ácido nicotínico}

O ácido nicotínico reduz a ação da lipase tecidual nos adipócitos, levando à menor liberação de ácidos graxos livres para a corrente sangüínea. Como conseqüência, reduz-se a síntese de TG pelos hepatócitos. Reduz o LDL-C em 5\% a 25\%, aumenta o HDL-C em 15 a 35\% e diminui os triglicérides em 20 a $50 \%$. Administrado isoladamente na forma tradicional, observou-se diminuição de $27 \%$ nos eventos coronários agudos e, após 15 anos de acompanhamento (dez anos após a interrupção do medicamento), houve diminuição significativa da mortalidade total. Associado com estatinas, ou combinado com estatinas e resina, o ácido nicotínico reduziu a progressão anatômica da aterosclerose coronária e os principais desfechos cardiovasculares.

O ácido nicotínico pode ser utilizado em pacientes com HDL-C baixo isolado, mesmo sem hipertrigliceridemia associada, e como alternativa aos fibratos e estatinas ou em associação com esses fármacos em portadores de hipercolesterolemia, hipertrigliceridemia ou dislipidemia mista (recomendação Ila, nível de evidência A). Devido a menor tolerabilidade com a forma de liberação imediata (rubor, prurido) e à descrição de hepatotoxicidade com a forma de liberação lenta, tem sido preconizado seu uso na forma de liberação intermediária, com melhor perfil de tolerabilidade. Como os efeitos adversos relacionados ao rubor facial ou prurido ocorrem com maior freqüência no início do tratamento, recomenda-se dose inicial de $500 \mathrm{mg}$ ao dia com aumento gradual, em geral para 750 mg e depois para $1000 \mathrm{mg}$, com intervalos de quatro semanas a cada titulação de dose, buscando-se atingir 1 a 2 g diárias. O pleno efeito sobre o perfil lipídico apenas será atingido com o decorrer de vários meses de tratamento. Com a forma de liberação intermediária e o uso de doses atualmente mais baixas de niacina, outros efeitos como alterações gastrintestinais, hiperglicemia e hiperuricemia tornaram-se mais raros. De fato, estudo recente avaliando as modificações na hemoglobina glicada em diabéticos mostrou que pacientes tratados com 1 $\mathrm{g}$ de niacina isolada ou associada com estatina não tiveram modificações neste parâmetro glicídico. Entretanto, pequeno 
aumento da hemoglobina glicada foi verificado com a dose de 1,5 $\mathrm{g}(0,02 \%$ de aumento na $\mathrm{HbA} 1 \mathrm{c})$. Por outro lado, estes pacientes diabéticos com o uso de 1 ou 1,5 g de niacina tiveram substancial aumento de HDL-C (19\% e 24\%, respectivamente).

Ácidos graxos ômega 3

Os ácidos graxos omega-3 são derivados do óleo de peixes provenientes de águas frias e profundas, que reduzem a síntese hepática dos TG. Os mais importantes são o eicosapentaenóico (EPA) e o docosahexaenóico (DHA). Em altas doses (4 a 10 g ao dia) reduzem os triglicérides e aumentam discretamente o HDLC. Podem, entretanto, aumentar o LDL-C. Em portadores de doença arterial coronária, a suplementação de $1 \mathrm{~g} / \mathrm{dia}$ de omega3 em cápsulas, reduziu em 10\% os eventos cardiovasculares (morte, infarto do miocárdio, acidente vascular cerebral). Portanto, os ácidos graxos ômega-3 podem ser utilizados como terapia adjuvante na hipertrigliceridemia ou em substituição a fibratos, niacina ou estatinas em pacientes intolerantes.

\section{Medicamentos que atuam no HDL-C}

Novos fármacos com ação específica de elevar o HDL-C estão em desenvolvimento e os primeiros ensaios clínicos estão em andamento. Até o momento em que foi concluída esta Diretriz, fibratos e ácido nicotínico são as opções disponíveis para tratamento de indivíduos com HDL-C baixo, particularmente naqueles com aumento dos TG.

Evidências do benefício da monoterapia com estes fármacos são ainda escassas. Estudos da monoterapia com fibratos têm demonstrado resultados contraditórios e as evidências favoráveis são advindas de análises retrospectivas de subpopulações destes estudos que manifestavam síndrome metabólica. A monoterapia com ácido nicotínico de liberação imediata reduziu moderadamente a mortalidade cardiovascular (11\%) no estudo Coronary Drug Project, ao longo de 10 anos de tratamento. Seu uso, no entanto, tem sido limitado pelos freqüentes efeitos colaterais, como descrito acima.

A combinação terapêutica de estatinas com fibratos e/ou ácido nicotínico na forma de liberação intermediária, tem despertado grande interesse em função da evidência de regressão de volume de ateroma coronário e redução de eventos clínicos em estudos com pequenas casuísticas $(<200$ indivíduos). Novos estudos estão em andamento e deverão definir a recomendação desta terapêutica na prática clínica.

\section{Produtos confeccionados em farmácias de manipulação}

A ciência farmacêutica tem sido desenvolvida numa premissa essencial de garantir segurança e eficácia terapêutica. Para tanto, estudos são realizados para garantir a segurança, a biodisponibilidade e a eficácia de ambos, o princípio ativo e a forma farmacêutica que o veiculará. Desta forma, esta Diretriz não recomenda a utilização de produtos confeccionados em farmácias de manipulação e de similares cuja bioequivalência ao medicamento original não tenham sido testadas e comprovadas (grau de recomendação III, nível de evidência D).

\section{Interações medicamentosas}

A principal interação entre hipolipemiantes ocorre entre os fibratos e as estatinas. Embora estes fármacos tenham essa característica, não há contra-indicação ao uso concomitante de ambos sob vigilância clínica cuidadosa. Esta interação é particularmente encontrada nas associações com o genfibrozil, devendo-se, por isso, evitar usar este fibrato nas associações. Além dos fibratos, a associação de estatinas com o ácido nicotínico também deve ser realizada com cautela. A possível interação entre os medicamentos hipolipemiantes e outros produtos de utilização freqüente deve ser sempre lembrada devendo ser consultadas tabelas de interações antes da associação de vários medicamentos em um mesmo paciente.

\section{DISLIPIDEMIAS EM GRUPOS ESPECIAIS}

\section{Dislipidemias graves}

Os portadores de formas graves de dislipidemia e que apresentam pequena ou mesmo nenhuma resposta ao uso de hipolipemiantes em doses habituais devem ser encaminhados a centro de referência. Esse tratamento exige monitorização laboratorial intensiva e seguimento clínico mais freqüente em virtude da maior incidência de eventos adversos. Em centros de referência, doses elevadas, associação de medicamentos e medidas alternativas podem ser adotadas (aféreses, anastomose ileal parcial, transplante de fígado e terapêutica genética).

\section{Diabete melito}

Nos diabéticos, as dislipidemias habitualmente encontradas são hipertrigliceridemia, redução do HDL-C e aumento do volume de partículas de LDL pequena e densa. Os níveis absolutos de LDL-C, no entanto, são similares nos diabéticos e na população em geral. Apesar disto, a redução da colesterolemia por meio do tratamento com estatinas em diabéticos tipo 2 é um elemento crucial na prevenção da doença aterosclerótica.

Nos últimos anos, estudos clínicos bem controlados têm demonstrado que a redução do LDL-C nos diabéticos promove benefício similar à redução do LDL-C em pacientes com doença coronária manifesta. Com base nesses dados, a III Diretriz Brasileira sobre Dislipidemias e Prevenção da Aterosclerose, de 2001, apontou como meta terapêutica LDL-C $<100 \mathrm{mg} / \mathrm{dL}$ em ambos diabéticos e pacientes com doença aterosclerótica clinicamente manifesta. Nos últimos meses, estudos clínicos consistentes demonstraram que a redução do LDL-C $<70 \mathrm{mg} / \mathrm{dL}$ promove redução adicional na manifestação de eventos cardiovasculares em pacientes com doença coronária quando comparada à redução para a meta de LDL-C $<100 \mathrm{mg} / \mathrm{dL}$. Assim, em consistência com a III Diretriz, a meta $<70 \mathrm{mg} / \mathrm{dL}$ pode ser considerada opcional para os pacientes diabéticos, uma vez que estes são considerados como de risco equivalente aos portadores da doença aterosclerótica (grau de recomendação Ila, nível de evidência D).

Doença renal crônica

Cerca de 90\% dos pacientes com doença renal crônica 


\section{Diretriz}

(DRC) apresentam hipercolesterolemia. Hipertrigliceridemia, HDL-C < 35 mg/dL e Lp(a) > 30 mg/dL ocorrem cada uma em $60 \%$ dos pacientes. No entanto, a prevalência pode variar conforme a gravidade da DRC e o tratamento dialítico. Após transplante renal, os níveis de HDL-C e de Lp(a) tendem a normalizar nestes pacientes.

Com relação à síndrome nefrótica, tanto a hipercolesterolemia como a hipertrigliceridemia têm sido descritas. Estudos "in vitro" sugerem que a pressão oncótica baixa do plasma, própria da síndrome nefrótica, estimula diretamente a transcrição do gene da apolipoproteína B, aumentando a síntese das lipoproteínas que contêm essa apolipoproteína. A redução do catabolismo tem também papel importante na fisiopatogenia da dislipidemia observada na síndrome nefrótica. A regressão da síndrome nefrótica, espontânea ou após tratamento medicamentoso, reverte a dislipidemia.

Mais importante que a indução da dislipidemia pela DRC é o papel desta e o do tratamento com hipolipemiante na evolução da doença renal. Em alguns estudos, o tratamento da hipercolesterolemia com estatinas tem demonstrado favorecer a preservação e, ocasionalmente, a melhora da função renal em indivíduos em prevenção primária e secundária. No entanto, embora exista consenso com relação à necessidade de tratamento das dislipidemias nos indivíduos com DRC, o volume de evidências é insuficiente para o esclarecimento integral sobre este benefício. Em outras palavras, não há evidência de que, na ausência de rabdomiólise, o uso de estatina possa causar ou acentuar a disfunção renal. Pacientes com DRC, no entanto, pelo risco cardiovascular acentuado que possuem, devem ser investigados e tratados com hipolipemiantes com a finalidade de prevenir a doença cardiovascular. Neste contexto, esta Diretriz adotou a presença de microalbuminúria, clearance de creatinina $<60 \mathrm{~mL} /$ minuto e/ou creatinina superior a $1,5 \mathrm{mg} / \mathrm{dL}$ como fator agravante (Tabela VII), elevando o seu portador à categoria de risco imediatamente superior (grau de recomendação lla e nível de evidência B). Todo indivíduo portador de DRC deve, portanto, ser avaliado quanto à presença de dislipidemias (grau de recomendação lla e nível de evidência B) e sua hipercolesterolemia tratada conforme a meta indicada ao seu risco de eventos cardiovasculares (Tabela IX) (grau de recomendação lla, nível de evidência B). Para este fim, o intervalo entre a sessão de diálise e a coleta das amostras deve ser de, no mínimo, 12 horas.

Cuidado especial deve ser feito ao risco de rabdomiólise naqueles indivíduos com redução acentuada da função renal (clearance $<60 \mathrm{~mL} /$ minuto) que passarem a fazer uso de estatinas ou fibratos. Nestes deve-se evitar o uso de genfibrozil e preferir estatinas com menores taxas de excreção renal conforme Tabela XIII (grau de recomendação Ila, nível de evidência B).

\section{Hipotireoidismo}

A dislipidemia do hipotireoidismo é caracterizada pelo aumento das concentrações plasmáticas do LDL-C, conseqüente ao decréscimo do número de receptores hepáticos para a remoção destas partículas. Nos indivíduos com hipotireoidismo e obesidade, observa-se hipertrigliceridemia em decorrência do aumento da produção hepática das partículas de VLDL, da lipólise diminuída dos triglicérides séricos e, em alguns
Tabela XIII - Excreção renal e meia-vida de eliminação das estatinas

\begin{tabular}{lcc} 
Fármaco & Excreção renal (\%) & Meia-vida (horas) \\
\hline Sinvastatina & 13 & 2 \\
\hline Lovastatina & 10 & 3 \\
\hline Pravastatina & 20 & 1,8 \\
\hline Fluvastatina & 6 & 1,2 \\
Atorvastatina & $<5$ & 14 \\
\hline Rosuvastatina & 10 & 19
\end{tabular}

indivíduos com o genótipo E-2/E-2, da remoção lenta dos remanescentes de VLDL. As alterações nos lípides plasmáticos ocorrem tanto no hipotireoidismo manifesto clinicamente, como na forma subclínica. No entanto, mesmo após reposição hormonal alguns indivíduos permanecem dislipidêmicos, demonstrando a coexistência da dislipidemia primária. Por isso, após reposição hormonal, deve-se aferir o perfil lipídico para avaliar a necessidade de tratamento adicional. O tratamento com estatinas não está contra-indicado nesses indivíduos. No entanto, atenção especial deve ser dada à monitorização da miotoxicidade após início das estatinas nos pacientes com hipotireoidismo não tratado, por terem eles risco aumentado de miosite (grau de recomendação lla, nível de evidência $\mathrm{D}$ ). A reposição hormonal corrige a dislipidemia induzida pelo hipotireoidismo.

\section{Hepatopatias crônicas}

A cirrose biliar, a colangite esclerosante e outras hepatopatias que cursam com colestase, podem ser acompanhadas de hipercolesterolemia significativa. Entretanto, a colesterolemia não se correlaciona aos níveis plasmáticos de bilirrubina. Com relação às doenças hepáticas não-colestáticas crônicas e à cirrose hepática, não há contra-indicação à terapia de prevenção com estatinas. Em casos de surgimento de icterícia, elevação de bilirrubina direta ou aumento do tempo de protrombina, a estatina deve ser suspensa (grau de recomendação Ilb, nível de evidência D). A estatina também deverá ser suspensa, na ocasião do surgimento de nova doença hepática, quando não for possível excluí-la como agente causal (grau de recomendação Ilb, nível de evidência D).

\section{Síndrome da imunodeficiência adquirida (SIDA)}

Antes do surgimento dos inibidores de protease (IP), relatos e séries de casos descreveram aumento da incidência de eventos vásculo-trombóticos agudos nos indivíduos portadores do vírus ou da Síndrome da Imunodeficiência Adquirida (SIDA). Esses achados estavam circunscritos pela gravidade da doença imunológica e foram atribuídos à trombofilia e à acentuação do risco aterogênico pela redução de HDL-C e elevação de TG e Lp(a) naqueles indivíduos. A utilização da terapia antiretroviral altamente ativa (HAART - Highly Active Anti-Retroviral Therapy) para o tratamento da SIDA permitiu atenuação acentuada da deficiência imunológica e, conseqüentemente, da morbidade e mortalidade associadas à doença. Entretanto, o aumento da sobrevida trouxe relevância para o risco de 
eventos cardiovasculares precoces em portadores da SIDA. Além disso, surgiram efeitos colaterais metabólicos decorrentes desta terapêutica, em especial do uso dos IP, caracterizada por lipodistrofia, resistência à insulina e dislipidemia mista. Os indivíduos sob tratamento com IP apresentam, freqüentemente, elevações acentuadas de triglicérides e de Não-HDL-C, além da redução de HDL-C. Combinados, o aumento da sobrevida pelo benefício do HAART e o aumento do perfil aterogênico pela SIDA e pelo tratamento com os IP acentuaram a incidência de eventos cardiovasculares agudos e apontaram para a necessidade de terapia preventiva nos indivíduos soropositivos ou portadores da SIDA.

Com base nessas evidências, esta Diretriz recomenda que a avaliação do risco aterosclerótico através do ERF e do perfil lipídico nos indivíduos soropositivos deva ser feita na avaliação inicial, antes da instituição do HAART (grau de recomendação IIA, nível de evidência C). Para indivíduos estratificados como de baixo risco cardiovascular, com valores lipídicos dentro dos limites desejáveis e sem terapia anti-retroviral, a avaliação deve ser repetida a cada dois anos (grau de recomendação Ila, nível de evidência D). Neste grupo e, em particular, quando o perfil de risco for considerado elevado, deve ser estimulada a adoção de estilo de vida saudável, com ênfase para interrupção do tabagismo. Para pacientes com indicação de terapia anti-retroviral, recomenda-se reavaliação um mês após o início da medicação e no seguimento, a cada três meses (grau de recomendação Ila, nível de evidência D). Dentre estes, cerca de dois terços manifestaram dislipidemia mista com indicação terapêutica. Tendo como ação preferencial a adoção de estilo de vida saudável, as opções terapêuticas incluem ainda o uso de hipolipemiantes.

Medicamentos anti-retrovirais são preferencialmente metabolizados pelo CYP P450 3A4 e interações com estatinas modificam os níveis séricos e a eficácia dos IP, por compartilharem os mesmos sítios de metabolização hepática. Portanto, deve ser dada preferência para estatinas que atuem em sítios de metabolização distintos, como a pravastatina e fluvastatina, e evitar aquelas com metabolização exclusiva pelo CYP P450 3A4, como a sinvastatina (grau de recomendação Ila, nível de evidência D). A atorvastatina pode ser usada com cautela e existem dados favoráveis, porém limitados, com a rosuvastatina até o presente (grau de recomendação Ilb, nível de evidência D). Fibratos e os ácidos graxos ômega-3 podem ser administrados em concomitância aos IP (grau de recomendação Ila, nível de evidência B). Terapia combinada usando estatinas e fibratos é recomendada para dislipidemias mistas graves, entretanto, como para as demais condições clínicas, a associação com genfibrozil deve ser evitada. Nestes casos, recomenda-se rigoroso monitoramento de toxicidade muscular por avaliação de sintomas de miopatia e dosagens de CK (grau de recomendação Ila, nível de evidência D).

\section{Síndromes isquêmicas agudas (SIA)}

As alterações lipídicas mais freqüentemente observadas nos pacientes com SIA são: aumento dos TG e diminuição do LDL-C e do HDL-C. Nas primeiras 24 horas após o início dos sintomas, entretanto, o perfil lipídico corresponde aos valores usuais dos pacientes. Além de aumentar a aderência ao tratamento, evidências científicas indicam benefício no uso precoce das estatinas nesta população. Portanto, o uso de estatinas está indicado para os indivíduos com síndromes coronárias agudas, tendo como meta terapêutica LDL-C $<70$ mg/dL (grau de recomendação I, nível de evidência B).

Idosos (> 65 anos)

Nessa faixa etária, deve ser dada especial atenção a causas secundárias de dislipidemias, principalmente hipotireoidismo, diabete melito e insuficiência renal crônica. Nos idosos em prevenção secundária, mantêm-se as mesmas recomendações feitas aos demais pacientes (grau de recomendação I, nível de evidência B). Naqueles em prevenção primária, embora as evidências sejam preliminares, o tratamento com estatinas pode ser benéfico na prevenção de eventos coronários (grau de recomendação Ila, nível de evidência B), acidentes vasculares cerebrais (grau de recomendação lla, nível de evidência B) e preservação da função cognitiva (grau de recomendação Ilb, nível de evidência B).

\section{Mulheres em idade fértil}

A terapia com estatinas deve ser evitada em mulheres em idade fértil e sem contracepção adequada ou que desejem engravidar (grau de recomendação Ila, nível de evidência D). Os fibratos podem ser considerados em casos de hipertrigliceridemia muito grave (TG > $1000 \mathrm{mg} / \mathrm{dL}$ ), como parte de análise de risco/benefício para gestantes (pela alta mortalidade da mãe e do feto pela pancreatite aguda durante a gravidez), entretanto, o tratamento mais seguro e recomendado nestas situações é a plasmaferese (grau de recomendação Ila, nível de evidência D).

\section{Mulheres no período climatérico pós-menopausal}

Embora a terapia de reposição hormonal (TRH) em mulheres após a menopausa possa reduzir o LDL-C em até 20-25\% e aumentar o HDL-C em até $20 \%$, as evidências disponíveis demonstram aumento discreto de risco cardiovascular em associação à TRH. Nas mulheres em prevenção primária com indicações ginecológicas para TRH (controle de sintomas vasomotores, osteoporose), sugere-se a terapia por período limitado, especialmente na presença de fatores de risco cardiovasculares (grau de recomendação I, nível de evidência A). A TRH deve ser evitada em mulheres com alto risco cardiovascular ou em prevenção secundária (grau de recomendação III, nível de evidência A). Naquelas em utilização de TRH que apresentam evento cardiovascular, a TRH deve ser interrompida (grau de recomendação III, nível de evidência A). As estatinas diminuem a morbi-mortalidade em mulheres portadoras de aterosclerose e após a menopausa, sendo os medicamentos de escolha para a prevenção de eventos clínicos (grau de recomendação I, nível de evidência A).

\section{Perioperatório}

Para todos os pacientes com indicação do uso de estatinas, a medicação deve ser mantida ou então iniciada, independentemente da natureza do procedimento cirúrgico proposto (grau de recomendação lla, nível de evidência B). Nos pacientes coronariopatas ou com alto risco cardiovascular, o tratamento com estatinas pode reduzir complicações atero- 


\section{Diretriz}

trombóticas no perioperatório de intervenções vasculares (grau de recomendação lla, nível de evidência B).

\section{Transplante cardíaco (TC)}

A presença de dislipidemia após TC está associada a maior incidência de doença vascular do enxerto. Portanto, apesar da falta de evidências, o tratamento com estatinas deve ser indicado nos indivíduos com TC e dislipidemia (grau de recomendação lla, nível de evidência D). Nestes casos, devese monitorar o risco de toxicidade muscular devido à interação das estatinas com a ciclosporina.

\section{Doenças reumáticas auto-imunes}

Doenças reumáticas auto-imunes estão associadas a maiores índices de mortalidade e morbidade cardiovascular. Esta associação se deve ao aumento da prevalência de fatores de risco convencionais para aterosclerose, ao uso de fármacos com potencial efeito aterogênico como corticóides e à participação da anormalidade inflamatória e auto-imune no processo aterogênico e na trombogênese. Várias doenças reumáticas auto-imunes associam-se à manifestação precoce da aterosclerose. As mais estudadas são o Lupus Eritematoso Sistêmico, Artrite Reumatóide, Síndrome Antifosfolípide, Esclerose Sistêmica Progressiva, Síndrome de Sjögren e Vasculite Sistêmica Primária. Potencialmente, a presença dessas doenças pode equivaler a alto risco cardiovascular, a exemplo do diabete melito. No entanto, o volume de evidências é restrito para que sejam criadas normatizações dessa natureza. À luz dos conhecimentos disponíveis, essa Diretriz recomenda atenção especial ao estilo de vida e ao controle dos fatores de risco nos indivíduos com doença reumática auto-imune (grau de recomendação lla, nível de evidência D). Caso seja necessário o uso de fármacos hipolipemiantes, sua utilização deve ser regida pelas mesmas normas recomendadas nesta diretriz, para as populações não portadoras de doenças auto-imunes.

\section{Bibliografia recomendada}

- Report from the Laboratory Standardization Panel of the National Cholesterol Education Program - Recommendations for Improving Cholesterol Measurement. NIH Publication $\mathrm{N}^{\circ}$ 93-2964, January 1993.

- Alberti KG, Zimmet P, Shaw J. Metabolic syndrome--a new world-wide definition. A Consensus Statement from the International Diabetes Federation. Diabet Med. 2006; 23(5): 469-80.

- IDF Clinical Guidelines Task Force. Global Guideline for Type 2 Diabetes: recommendations for standard, comprehensive, and minimal care. Diabet Med. 2006; 23(6): 579-93.

- Executive Summary of The Third Report of The National Cholesterol Education Program (NCEP) Expert Panel on Detection, Evaluation, And Treatment of High Blood Cholesterol In Adults (Adult Treatment Panel III). JAMA 2001; 285: 2486-97.

- AHA; ACC; National Heart, Lung, and Blood Institute. AHA/ACC guidelines for secondary prevention for patients with coronary and other atherosclerotic vascular disease: 2006 update endorsed by the National Heart, Lung, and Blood Institute. J Am Coll Cardiol 2006; 47: 2130-9.

- The Lipid Research Clinics Coronary Primary Prevention Trial results. I. Reduction in incidence of coronary heart disease. JAMA 1984; 251(3): 351-64.

- The Lipid Research Clinics Coronary Primary Prevention Trial results. II. The relationship of reduction in incidence of coronary heart disease to cholesterol lowering. JAMA 1984; 251(3): 365-74.

- Frick MH, Elo O, Haapa K, Heinonen OP, Heinsalmi P, Helo P, et al. Helsinki Heart Study: primary-prevention trial with gemfibrozil in middle-aged men with dyslipidemia. Safety of treatment, changes in risk factors, and incidence of coronary heart disease. N Engl J Med 1987; 317(20): 1237-45.

- Randomised trial of cholesterol lowering in 4444 patients with coronary heart disease: the Scandinavian Simvastatin Survival Study (4S). Lancet 1994; 344: 1383-9.

- Shepherd J, Cobbe SM, Ford I, Isles CG, Lorimer AR, MacFarlane PW, et al. Prevention of coronary heart disease with pravastatin in men with hypercholesterolemia. West of Scotland Coronary Prevention Study Group. N Engl J Med 1995; 333: 1301-7.

- Sacks FM, Pfeffer MA, Moye LA, Rouleau JL, Rutherford JD, Cole TG, et al. The effect of pravastatin on coronary events after myocardial infarction in patients with average cholesterol levels. Cholesterol and Recurrent Events Trial investigators. N Engl J Med 1996; 335: 1001-9.

- Downs JR, Clearfield M, Weis S, Whitney E, Shapiro DR, Beere PA, et al. Primary prevention of acute coronary events with lovastatin in men and women with average cholesterol levels: results of AFCAPS/TexCAPS. Air Force/Texas Coronary Atherosclerosis Prevention Study. JAMA 1998; 279: 1615-22.

- Prevention of cardiovascular events and death with pravastatin in patients with coronary heart disease and a broad range of initial cholesterol levels. The Long-Term Intervention with Pravastatin in Ischaemic Disease (LIPID) Study Group. N Engl J Med 1998; 339(19): 1349-57.

- Rubins HB, Robins SJ, Collins D, Fye CL, Anderson JW, Elam $M B$, et al. Gemfibrozil for the secondary prevention of coronary heart disease in men with low levels of highdensity lipoprotein cholesterol. Veterans Affairs High-Density Lipoprotein Cholesterol Intervention Trial Study Group. N Engl J Med 1999; 341(6): 410-8.

- Dietary supplementation with n-3 polyunsaturated fatty acids and vitamin E after myocardial infarction: results of the GISSI-Prevenzione trial. Gruppo Italiano per lo Studio della Sopravvivenza nell'Infarto miocardico. Lancet 1999; 354(9177): 447-55.

- MRC/BHF Heart Protection Study of cholesterol lowering with simvastatin in 20,536 high-risk individuals: a randomised placebo-controlled trial. Lancet 2002; 360(9326): 7-22.

- Shepherd J, Blauw GJ, Murphy MB, Bollen EL, Buckley BM, Cobbe SM, et al. Pravastatin in elderly individuals at risk of vascular disease (PROSPER): a randomised controlled trial. Lancet 2002; 360(9346): 1623-30.

- Collins R, Armitage J, Parish S, Sleigh P, Peto R; Heart 
Protection Study Collaborative Group. MRC/BHF Heart Protection Study of cholesterol-lowering with simvastatin in 5963 people with diabetes: a randomised placebo-controlled trial. Lancet 2003; 361: 2005-16.

- Cannon CP, Braunwald E, McCabe CH, et al. Intensive versus moderate lipid lowering with statins after acute coronary syndromes. N Engl J Med 2004; 350:1495-504.

- LaRosa JC, Grundy SM, Waters DD, et al. Intensive lipid lowering with atorvastatin in patients with stable coronary disease. N Engl J Med 2005; 352: 1425-35.

- Pedersen TR, Faergeman O, Kastelein JJ, et al. Incremental Decrease in End Points Through Aggressive Lipid Lowering (IDEAL) Study Group. High-dose atorvastatin vs usualdose simvastatin for secondary prevention after myocardial infarction: the IDEAL study: a randomized controlled trial. JAMA 2005; 294:2437-45

- Pasternak RC, Smith SC, Jr., Bairey-Merz CN, Grundy SM, Cleeman JI, Lenfant C. ACC/AHA/NHLBI Clinical Advisory on the Use and Safety of Statins. Circulation 2002; 106(8): 1024-8.

- Baigent C, Keech A, Kearney PM, et al, Cholesterol Treatment Trialists' (CTT) Collaborators. Efficacy and safety of cholesterol-lowering treatment: prospective meta-analysis of data from 90,056 participants in 14 randomised trials of statins. Lancet 2005;366:1267-78. Erratum in: Lancet 2005;366:1358.

- Ballantyne CM, Abate N, Yuan Z, King TR, Palmisano J. Dose comparison study of the combination of ezetimibe and simvastatin (Vytorin) versus atorvastatin in patients with hypercholesterolemia: the Vytorin Versus Atorvastatin (VYVA) study. Am Heart J 2005;149: 464-73. Erratum in: Am Heart J 2005;149:882.

- de Lemos JA, Blazing MA, Wiviott SD, et al., A to Z Investigators. Early intensive vs a delayed conservative simvastatin strategy in patients with acute coronary syndromes: phase $Z$ of the A to Z trial. JAMA 2004;292: 1307-16.

- Thompson PD, Buchner D, Pina IL, et al., American Heart Association Council on Clinical Cardiology Subcommittee on Exercise, Rehabilitation, and Prevention; American Heart Association Council on Nutrition, Physical Activity, and Metabolism Subcommittee on Physical Activity. Exercise and physical activity in the prevention and treatment of atherosclerotic cardiovascular disease: a statement from the Council on Clinical Cardiology (Subcommittee on Exercise, Rehabilitation, and Prevention) and the Council on Nutrition, Physical Activity, and Metabolism (Subcommittee on Physical Activity). Circulation 2003;107:3109 -16.

- American Diabetes Association. Standards of medical care in diabetes. Diabetes Care 2004;27 Suppl 1:S15-35.

- ALLHAT Officers and Coordinators for the ALLHAT Collaborative Research Group. The Antihypertensive and Lipid-Lowering Treatment to Prevent Heart Attack Trial. Major outcomes in moderately hypercholesterolemic, hypertensive patients randomized to pravastatin vs usual care: the Antihypertensive and Lipid-Lowering Treatment to Prevent Heart Attack Trial (ALLHAT-LLT). JAMA 2002;288:2998 -3007.

- Sever PS, Dahlof B, Poulter NR, et al, ASCOT investigators. Prevention of coronary and stroke events with atorvastatin in hypertensive patients who have average or lower-thanaverage cholesterol concentrations, in the Anglo-Scandinavian Cardiac Outcomes Trial-Lipid Lowering Arm (ASCOT-LLA): a multicentre randomised controlled trial. Lancet 2003; 361:1149-58.

- Grundy SM, Vega GL, McGovern ME, et al. Efficacy, safety, and tolerability of once-daily niacin for the treatment of dyslipidemia associated with type 2 diabetes: results of the assessment of diabetes control and evaluation of the efficacy of niaspan trial. Arch Intern Med. 2002;162(14):1568-76

- Brown BG, Zhao XQ, Chait A, et al. Simvastatin and niacin, antioxidant vitamins, or the combination for the prevention of coronary disease. N Engl J Med. 2001;345(22):1583-92.

- Statins, cardiovascular disease and drug safety. Am J Cardiol 2006; 97(Suppl):3C-97C. 